
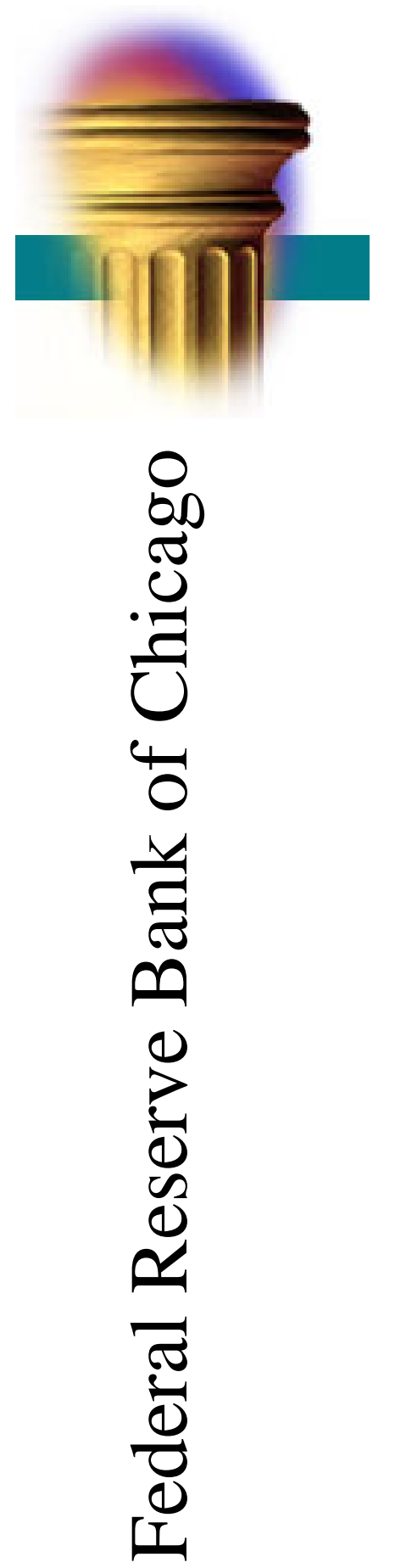

\title{
The Term Structure and Inflation Uncertainty
}

Tomas Breach, Stefania D’Amico, and Athanasios Orphanides

December 2016

WP 2016-22 


\title{
The Term Structure and Inflation Uncertainty
}

\author{
Tomas Breach, Stefania D'Amico, and Athanasios Orphanides*
}

December 12, 2016

\begin{abstract}
This paper develops and estimates a Quadratic-Gaussian model of the U.S. term structure that can accommodate the rich dynamics of inflation risk premia over the 1983-2013 period by allowing for time-varying market prices of inflation risk and incorporating survey information on inflation uncertainty in the estimation. The model captures changes in premia over very diverse periods, from the inflation scare episodes of the 1980s, when perceived inflation uncertainty was high, to the more recent episodes of negative premia, when perceived inflation uncertainty has been considerably smaller. A decomposition of the nominal ten-year yield suggests a decline in the estimated inflation risk premium of 1.7 percentage points from the early 1980s to mid-1990s. Subsequently, its predicted value has fluctuated around zero and turned negative at times, reaching its lowest values (about -0.6 percentage points) before the latest financial crisis, in 2005-2007, and during the subsequent weak recovery, in 2010-2012. The model's ability to generate sensible estimates of the inflation risk premium has important implications for the other components of the nominal yield: expected real rates, expected inflation, and real risk premia.
\end{abstract}

Keywords: Quadratic-Gaussian Term Structure Models, Inflation Risk Premium, Survey Forecasts, Hidden Factors.

JEL Classification: G12, E43, E44, C58

*Breach: Federal Reserve Bank of Chicago. E-mail: tbreach@frbchi.org. D'Amico: Federal Reserve Bank of Chicago. E-mail: sdamico@frbchi.org. Orphanides: MIT Sloan School of Management. E-mail: athanasios.orphanides@mit.edu. For helpful comments, discussions, and suggestions we thank Bob Barsky, Alejandro Justiniano, Don Kim, Thomas King, Anna Paulson, Hiro Tanaka, Min Wei, and seminar participants at the Federal Reserve Board and the Federal Reserve Bank of Chicago. The views expressed here do not reflect official positions of the Federal Reserve. 


\section{Introduction}

Longer-term nominal yields contain rich information about real interest rates and inflation rates that market participants expect to prevail in the future. Extracting this valuable information, however, is complicated by the presence of unobservable inflation risk premia (IRP) and real risk premia (RRP) that are widely acknowledged to vary over time.

Monetary policymakers are keenly interested in understanding these premia for multiple reasons. The IRP embedded in nominal yields may reflect factors such as uncertainty about inflation and the credibility of the monetary authority (e.g., Argov et al. 2007; Palomino, 2012; Du et al., 2016), which may evolve over time with the ability of the central bank to successfully communicate its policy strategy and deliver on its inflation objective. Changes in perceptions of inflation risks, such as the inflation scare episodes of the 1980s (Goodfriend, 1993) or the risk of deflation following the last financial crisis (Kitsul and Wright, 2013), may cause abrupt changes in long-term yields not necessarily associated with shifts in expectations of future interest rates or inflation. At times, significant changes in risk premia may complicate the transmission of monetary policy to longer-term rates, particularly when premia move in the direction opposite to expectations of short-term rates, as has apparently been the case in the "conundrum" period (2004-06) and the "taper tantrum" episode (May-June 2013). Understanding inflation uncertainty and associated risk premia is important for the appropriate risk management of monetary policy. (Evans et al, 2015; and Feldman et al, 2016).

In recent years, a new generation of dynamic term structure models has been developed to estimate the various components of the term structure by allowing flexible specifications of risk premia while maintaining analytical tractability (e.g., Dai and Singleton, 2000; Duffee, 2002). Despite considerable progress in modelling the term structure, estimation of the IRP has proven challenging. Alternative specifications estimated over different periods have resulted in a broad range of results (surveyed in Bekaert and Wong, 2010). Term structure models estimated using data prior to the last financial crisis (e.g., Ang, Bekaert, and Wei, 2008; Buraschi and Jiltsov, 2005; and Chernov and Mueller, 2012) report estimates of the IRP that are larger in magnitude and mainly positive. In contrast, models focusing on more recent data (e.g., Abrahams et al, 2013; Grishchenko and Huang, 2013; and Fleckenstein, Longstaff, and Lustig, 2014), deliver values of the IRP that are smaller in magnitude and often negative, especially at shorter maturities.

One factor that could explain fluctuations in the IRP over time is the variation in the level of actual and perceived inflation uncertainty. Inflation uncertainty makes nominal bonds risky, as their real value is eroded by surprise inflation, and thus is expected to affect the associated risk premium. Although the specific channels may differ, a relation between inflation uncertainty and the IRP emerges in numerous models, as highlighted for example in the survey by Gurkaynak and Wright 
(2012). In the data, both actual inflation volatility and survey-based inflation uncertainty have declined notably since the 1980s (D'Amico and Orphanides, 2008), as the Federal Reserve adopted policies that gradually reestablished its credibility to keep inflation low and stable, following a period of monetary neglect. And as shown by D'Amico and Orphanides (2014), real-time measures of perceived inflation uncertainty contain meaningful information about future nominal bond excess returns that is not contained in current yields or forward spreads. Another potentially critical factor for the evolution of the IRP is the changing covariance between bond and stock returns, which affects the hedging characteristics of Treasury nominal bonds. As indicated in Campbell, Sunderam, and Viceira (2016), for example, the stockbond covariance was high and positive in the early 1980s but became negative in the 2000s, which in their model mainly reflects time-variation in inflation volatility and in the covariance between inflation and the real economy, with both accounting for significant changes in the sign and size of nominal bond risk premia.

We develop a Quadratic-Gaussian term structure model that is flexible enough to encompass very diverse dynamic behaviors of the IRP over extreme episodes like the early 1980s, characterized by high actual and expected inflation as well as high inflation uncertainty, and the post-2008 period, characterized by low inflation (and mild deflation) as well as very low expected inflation and inflation uncertainty. The richer dynamic of the IRP is achieved by having time-varying market prices of inflation risk in the model, which translates into time-varying inflation volatility and time-varying covariances between yield curve factors and inflation. To obtain reliable estimates of the parameters governing these sources of inflation risk and the IRP, we incorporate information from survey-based inflation uncertainty in the estimation. Using this new data input, which captures real-time perceptions of inflation risk, proves quite valuable for pinning down the dynamics of the IRP which, in turn, has important implications for the other components of nominal yields: expected real short-term rates, expected inflation, and the RRP. The key novelty of this approach is to tackle the difficulties in the estimation of the IRP by allowing for very flexible market prices of inflation risk and by using a real-time measure of inflation uncertainty.

Introducing survey-based information about second moments may also be seen as an extension of the approach developed in Kim and Orphanides (2012) and Chernov and Mueller (2012) who augment term structure models with information from survey first moments. Similarly to the first of these studies, we include survey forecasts of short-term interest rates to guard against estimation imprecision and bias due to the highly persistent nature of interest rates; and, similarly to the second study, we include survey forecasts of inflation that help pin down expected inflation and real rates over a long sample period for which TIPS yields are not available.

To account for the possibility that survey forecasts provide noisy information and to let the data determine the extent of this noise, following Kim and Orphanides (2012) we allow for unconstrained variances of the measurement errors around all 
forecasts in the estimation. Acknowledging the presence of measurement errors is particularly important for survey-based inflation uncertainty, which is an imputed variable derived from the subjective probability distributions in the Survey of Professional Forecasters (SPF) using the methodology in D'Amico and Orphanides (2008).

In addition, following the intuition in Duffee (2011) and motivated by preliminary regressions similar to those conducted by Joslin, Priebsch, and Singleton (2014), in our model inflation-related variables are not fully spanned by the current nominal yield curve. This is achieved through two modelling choices. First, we introduce a shock capturing short-run variations in CPI inflation that do not require a monetarypolicy response, such as, short-lived changes in energy and food prices. Second, one of the factors is hidden in the nominal yield curve and can only influence the first and second moments of inflation. In principle, both of these features can be important because, while the conditional volatility of the Brownian shock specific to CPI affects inflation uncertainty and risk premia but not the forecast of inflation (i.e., its expected value is zero), the hidden factor can influence expected inflation. Moreover, the conditional volatility of the innovations to the hidden factor can also contribute to fluctuations in inflation uncertainty and risk premia.

The resulting model produces IRP estimates at the 10-year horizon that are larger and positive in the 1980s, then decline by about 1.7 percentage points by the mid 1990s, and subsequently become negative at times, for example during the conundrum period (2005-07) and during the deflation scare of 2010-2012. The estimates also capture episodes of sharp increases in the IRP, as for instance during the taper tantrum of May-June 2013. Further, despite being estimated without the use of TIPS yields, the model generates real yields that closely resemble those on TIPS, except for a residual very similar to the liquidity premium estimated in D'Amico, Kim, and Wei (2016). The model also does a good job at fitting the survey-based one-year expected inflation and inflation uncertainty, and it produces expected short-term rates that closely match those from survey forecasts. With regard to longer-term trends, the model captures the decline in long-term inflation expectations from the 1980 s to the 2000 s that is associated with the Federal Reserve's overall disinflationary policies over this period as well as the decline in long-term expectations of the short-term real interest rate reflecting the decline in the equilibrium real interest rate.

The rest of the paper is organized as follows. Section 2 sets up the QuadraticGaussian model. Section 3 compares our model to other key studies in the literature. Section 4 presents the state-space form of the model and the data. Section 5 provides details about the identification and estimation methodology. Section 6 presents the main model's empirical results and comparisons with alternative specifications, which help assess the contribution of key elements to its improved performance. Section 7 offers concluding remarks. 


\section{A Quadratic Gaussian Model}

In this section we develop a Quadratic Gaussian model of the term structure of interest rates that accommodates nominal yields, CPI inflation, survey-based expected inflation, expected interest rates, and inflation volatility.

\subsection{The basic building blocks}

We start with specifying the state factor dynamics under the physical measure, $\mathcal{P}$ :

$$
\left[\begin{array}{l}
d x_{t} \\
d z_{t}
\end{array}\right]=\left[\begin{array}{cc}
\kappa_{2 \times 2}^{x} & 0_{2 \times 1} \\
0_{1 \times 2} & \kappa_{1 \times 1}^{z}
\end{array}\right]\left[\begin{array}{c}
\left(\mu_{x}-x_{t}\right)_{2 \times 1} \\
\left(\mu_{z}-z_{t}\right)_{1 \times 1}
\end{array}\right] d t+\left[\begin{array}{cc}
\Sigma_{2 \times 2}^{x} & 0_{2 \times 1} \\
\sigma_{x, z} & \sigma_{z}
\end{array}\right]\left[\begin{array}{c}
d B_{t}^{x} \\
d B_{t}^{z}
\end{array}\right]
$$

where $z_{t}$ is a factor hidden in the nominal yield curve in the sense of Duffee (2011) but its shocks can be correlated with shocks relevant for nominal interest rates as indicated by the unconstrained $\sigma_{x, z}, B_{t}$ denotes a 3-dimensional standard Brownian motion, and thus all the factors are Gaussian.

The nominal pricing kernel under $\mathcal{P}$ is given by:

$$
\frac{d M_{t}^{N}}{M_{t}^{N}}=-r_{t}^{N} d t-\lambda_{t}^{N \prime} d B_{t}^{x}
$$

where the nominal short rate is an affine function of only two state variables:

$$
r_{t}^{N}=\rho_{0}^{N}+\rho_{1}^{N \prime} x_{t},
$$

and the 2-dimensional vector of the market price of nominal risk is given by:

$$
\lambda_{t}^{N}=\lambda_{0}^{N}+\Lambda^{N} x_{t}
$$

with $\Lambda^{N}$ being a $2 \times 2$ constant matrix that will be left unrestricted to allow for a flexible specification of the market price of nominal risk. However, by preventing $\lambda_{t}^{N}$ and $r_{t}^{N}$ from loading on $z_{t}$, we make sure that this factor is unspanned by nominal yields. ${ }^{1}$

The log price level follows the process

$$
d \log Q_{t}=\pi_{t} d t+\lambda_{t}^{q \prime} d B_{t}^{x^{*}}+\omega_{t} d B_{t}^{\perp}
$$

and is governed by $x_{t}^{*}=\left[x_{t}, z_{t}\right]$ rather than $x_{t}$, as the factors underlying the nominal yields are not sufficient to span inflation and expected inflation, which is affine in $x_{t}^{*}$ :

$$
\pi_{t}=\rho_{0}^{\pi}+\rho_{1}^{\pi \prime} x_{t}^{*}
$$

\footnotetext{
${ }^{1}$ This can be also achieved by imposing restrictions under the risk-neutral measure as in Duffee (2011), and we verified that results are not very sensitive to the way we impose the unspanning restrictions.
} 
and the two conditional volatility processes are given by

$$
\begin{aligned}
& \lambda_{t}^{q}=\lambda_{0}^{q}+\Lambda^{q} x_{t}^{*}, \\
& \omega_{t}=\omega_{0}+\omega_{1}^{\prime} x_{t}^{*},
\end{aligned}
$$

where $\rho_{0}^{\pi}$ and $\omega_{0}$ are scalars, $\rho_{1}^{\pi}$ and $\lambda_{0}^{q}$ are $3 \times 1$ vectors, $\omega_{1}^{\prime}$ is a $1 \times 3$ vector, $\Lambda^{q}$ is a $3 \times 3$ matrix, and $d B_{t}^{x^{*}} d B_{t}^{\perp}=0$. The orthogonal shock specific to the inflation process is supposed to capture, for instance, short-run variations in inflation that do not require a monetary-policy response and thus do not affect the nominal short rate (Kim, 2008). In particular, since we use total CPI in our estimation, not only it is important to have a separate shock for CPI innovations driven by changes in food and energy prices, but since these components are usually more volatile it is key to allow for time variation in the conditional volatility of this shock. Overall, this implies that we treat much of high-frequency variation in inflation as unspanned by interest rates.

The real pricing kernel is given by $M_{t}^{R}=M_{t}^{N} Q_{t}$, which by Ito's Lemma follows the dynamics:

$$
\frac{d M_{t}^{R}}{M_{t}^{R}}=\frac{d M_{t}^{N}}{M_{t}^{N}}+\frac{d Q_{t}}{Q_{t}}+\frac{d M_{t}^{N}}{M_{t}^{N}} \frac{d Q_{t}}{Q_{t}}=-r_{t}^{R} d t-\lambda_{t}^{R \prime} d B_{t}^{x^{*}}-\omega_{t} d B_{t}^{\perp}
$$

where the real short rate becomes a quadratic function of the state variables because of the interaction term $\frac{d M_{t}^{N}}{M_{t}^{N}} \frac{d Q_{t}}{Q_{t}}$, as each of these elements contains a state-dependent market price of risk, that is, $\lambda^{N}\left(x_{t}\right)$ and $\lambda^{q}\left(x_{t}^{*}\right)$, respectively:

$$
r_{t}^{R}=\rho_{0}^{R}+\rho_{1}^{R \prime} x_{t}^{*}+x_{t}^{* \prime} \Psi^{R} x_{t}^{*}
$$

all parameters are linked by the no-arbitrage conditions:

$$
\begin{aligned}
\rho_{0}^{R} & =\rho_{0}^{N}-\rho_{0}^{\pi}+\lambda_{0}^{N \prime} \lambda_{0}^{q}-\frac{1}{2}\left(\lambda_{0}^{q \prime} \lambda_{0}^{q}+\omega_{0}^{2}\right) \\
\rho_{1}^{R} & =\rho_{1}^{N}-\rho_{1}^{\pi}+\Lambda^{q \prime} \lambda_{0}^{N}+\Lambda^{N \prime} \lambda_{0}^{q}-\Lambda^{q \prime} \lambda_{0}^{q}-\omega_{0} \omega_{1} \\
\lambda_{t}^{R} & =\lambda_{t}^{N}-\lambda_{t}^{q} \\
\Psi^{R} & =\Lambda^{N^{\prime}} \Lambda^{q}-\frac{1}{2} \Lambda^{q^{\prime}} \Lambda^{q}-\frac{1}{2} \omega_{1} \omega_{1}^{\prime} .
\end{aligned}
$$

\subsection{Bond Pricing}

Under the risk-neutral measure, $\mathcal{Q}, x_{t}^{*}$ follows the dynamics:

$$
\begin{aligned}
d x_{t}^{*} & =\kappa\left(\mu-x_{t}^{*}\right) d t+\Sigma\left(d B_{t}^{x^{*}}+\lambda_{t}^{i} d t-\lambda_{t}^{i} d t\right) \\
& =\left(\kappa \mu-\kappa x_{t}^{*}-\Sigma \lambda_{0}^{i}-\Sigma \Lambda^{i} x_{t}^{*}\right) d t+\Sigma\left(d B_{t}^{x^{*}}+\lambda_{t}^{i} d t\right) \\
& =\widetilde{\kappa}\left(\widetilde{\mu}-x_{t}^{*}\right) d t+\Sigma d B_{t}^{\lambda}
\end{aligned}
$$


where

$$
\begin{aligned}
\widetilde{\kappa} & =\kappa+\Sigma \Lambda^{i} \\
\widetilde{\kappa} \widetilde{\mu} & =\kappa \mu-\Sigma \lambda_{0}^{i} \\
d B_{t}^{\lambda} & =d B_{t}^{x^{*}}+\lambda_{t}^{i} d t
\end{aligned}
$$

and $i=N, R$ indicating either the nominal or real risk neutral measure.

The price of a nominal and real zero-coupon bond with maturity $\tau$ is:

$$
\begin{aligned}
P_{t, \tau}^{i} & =\frac{E_{t}\left(M_{t+\tau}^{i}\right)}{M_{t}^{i}}=E_{t}^{\mathcal{Q}}\left(\exp \left(-\int_{t}^{t+\tau} r_{s}^{i} d s\right)\right) \\
& =\exp \left[A_{\tau}^{i}+B_{\tau}^{i \prime} x_{t}+x_{t}^{\prime} C_{\tau}^{i} x_{t}\right], \quad i=N, R
\end{aligned}
$$

with the solution satisfying the following differential equations:

$$
\begin{aligned}
& \frac{d A_{\tau}^{i}}{d \tau}=-\rho_{0}^{i}+B_{\tau}^{i / \widetilde{\kappa} \widetilde{\mu}}+\frac{1}{2} B_{\tau}^{i \prime} \Sigma \Sigma^{\prime} B_{\tau}^{i}+\operatorname{tr}\left[\Sigma^{\prime} C_{\tau}^{i} \Sigma\right] \\
& \frac{d B_{\tau}^{i}}{d \tau}=-\rho_{1}^{i}-\widetilde{\kappa}^{\prime} B_{\tau}^{i}+2 C_{\tau}^{i} \widetilde{\kappa} \widetilde{\mu}+2 C_{\tau}^{i} \Sigma \Sigma^{\prime} B_{\tau}^{i} \\
& \frac{d C_{\tau}^{i}}{d \tau}=-\Psi^{i}-C_{\tau}^{i} \widetilde{\kappa}-\widetilde{\kappa}^{\prime} C_{\tau}^{i}+2 C_{\tau}^{i} \Sigma \Sigma^{\prime} C_{\tau}^{i \prime} .
\end{aligned}
$$

In the case of nominal bonds (i.e., $i=N), C_{\tau}^{N}=0$, as in this model we start with specifying an affine nominal short rate and the real short rate inherits the quadratic component through the no arbitrage condition $M_{t}^{R}=M_{t}^{N} Q_{t}$, and therefore nominal bonds' prices preserve the same functional form usually obtained in affine Gaussian models. It follows that since $y_{t, \tau}^{i}=-\frac{1}{\tau} \log \left(P_{t, \tau}^{i}\right)$, nominal and real yields are equal to:

$$
\begin{gathered}
y_{t, \tau}^{N}=a_{\tau}^{N}+b_{\tau}^{N^{\prime}} x_{t} \\
y_{t, \tau}^{R}=a_{\tau}^{R}+b_{\tau}^{R \prime} x_{t}^{*}+x_{t}^{* \prime} c_{\tau}^{R} x_{t}^{*},
\end{gathered}
$$

where $a_{\tau}^{i}=-\frac{1}{\tau} A_{\tau}^{i}, b_{\tau}^{i}=-\frac{1}{\tau} B_{\tau}^{i}$, and $c_{\tau}^{i}=-\frac{1}{\tau} C_{\tau}^{i}$.

\subsection{Inflation: Expected and Unexpected}

Inflation between $t$ and $t+\tau$ is defined as:

$$
i_{t, \tau} \triangleq \frac{1}{\tau} \log \frac{Q_{t+\tau}}{Q_{t}}=\frac{1}{\tau}\left[\int_{0}^{\tau} \pi\left(x_{t+s}^{*}\right) d s+\int_{0}^{\tau} \lambda^{q}\left(x_{t+s}^{*}\right)^{\prime} d B_{s}^{x^{*}}+\int_{0}^{\tau} \omega\left(x_{t+s}^{*}\right)^{\prime} d B_{s}^{\perp}\right]
$$

and annual average expected inflation over horizon $\tau$ is given by: 


$$
E_{t}\left[i_{t+\tau}\right]=\frac{1}{\tau} \int_{0}^{\tau} E_{t}\left[\pi_{t+s}\right] d s
$$

therefore unexpected inflation can be expressed as follows:

$$
\begin{gathered}
i_{t, \tau}-E_{t}\left[i_{t+\tau}\right]=\frac{1}{\tau} \int_{0}^{\tau}\left(\pi_{t+s}-E_{t}\left[\pi_{t+s}\right]\right) d s+ \\
+\frac{1}{\tau}\left[\int_{0}^{\tau}\left(\lambda_{0}^{q}+\Lambda^{q} x_{t+s}^{*}\right)^{\prime} d B_{s}^{x^{*}}+\int_{0}^{\tau}\left(\omega_{0}+\omega_{1} x_{t+s}^{*}\right)^{\prime} d B_{s}^{\perp}\right]= \\
=\rho_{1}^{\pi \prime} \int_{0}^{\tau} \xi_{s} d s+\left(x_{t}^{*}-\mu\right)^{\prime}\left[\int_{0}^{\tau} e^{-\kappa s^{\prime}} \Lambda^{q \prime} d B_{s}^{x^{*}}+\int_{0}^{\tau} e^{-\kappa s^{\prime}} \omega_{1} d B_{s}^{\perp}\right]+ \\
\left(\lambda_{0}^{q}+\Lambda^{q} \mu\right)^{\prime} \int_{0}^{\tau} d B_{s}^{x^{*}}+\left(\omega_{0}+\omega_{1}^{\prime} \mu\right)^{\prime} \int_{0}^{\tau} d B_{s}^{\perp}+\int_{0}^{\tau} \xi_{s}^{\prime} \Lambda^{q \prime} d B_{s}^{x^{*}}+\int_{0}^{\tau} \xi_{s}^{\prime} \omega_{1} d B_{s}^{\perp} .
\end{gathered}
$$

It is easy to note that for the unexpected inflation to be time varying, that is, to be function of the factors $x_{t}^{*}$, it is sufficient that either $\Lambda^{q}$ or $\omega_{1}$ are different from zero, meaning that the time-varying market prices of inflation risk are the key features of the model permitting time variation in inflation volatility, which we derive below.

We can re-write the unexpected inflation in matrix form:

$$
\begin{gathered}
i_{t, \tau}-E_{t}\left[i_{t+\tau}\right]=\frac{1}{\tau}\left(C+D x_{t}^{*}\right)^{\prime} \zeta_{\tau} \\
C=\left[\begin{array}{c}
\rho_{1}^{\pi \prime} \\
\lambda_{0}^{q}+\Lambda^{q} \mu \\
-\mu \\
1 \\
\omega_{0}+\omega_{1}^{\prime} \mu \\
-\mu \\
1
\end{array}\right], D=\left[\begin{array}{c}
0_{3 \times 3} \\
0_{3 \times 3} \\
I_{3 \times 3} \\
0_{1 \times 3} \\
0_{1 \times 3} \\
I_{3 \times 3} \\
0_{1 \times 3}
\end{array}\right], \zeta_{\tau}=\left[\begin{array}{c}
\int_{0}^{\tau} \xi_{s} d s \\
\int_{0}^{\tau} d B_{s}^{x^{*}} \\
\int_{0}^{\tau} e^{-\kappa s^{\prime}} \Lambda^{q \prime} d B_{s}^{x^{*}} \\
\int_{0}^{\tau} \xi_{s}^{\prime} \Lambda^{q^{\prime}} d B_{s}^{x^{*}} \\
\int_{0}^{\tau} d B_{s}^{\perp} \\
\int_{0}^{\tau} e^{-\kappa s^{\prime}} \omega_{1} d B_{s}^{\perp} \\
\int_{0}^{\tau} \xi_{s}^{\prime} \omega_{1} d B_{s}^{\perp}
\end{array}\right]
\end{gathered}
$$

where $\int_{0}^{\tau} \xi_{s} d s=\kappa^{-1} \int_{0}^{\tau}\left(I_{3 \times 3}-e^{-\kappa s^{\prime}}\right) \Sigma d B_{s}^{x^{*}}$. By observing the elements in $\zeta_{\tau}$, it is easy to note that the unexpected inflation is driven by all four shocks in the model: the innovations to the yield factors, the innovations to the hidden factor, and the shock specific to CPI, as well as the conditional volatility of these shocks.

The inflation variance is a quadratic function of the state variables:

$$
\operatorname{var}\left(i_{t, \tau}\right)=\frac{1}{\tau^{2}} E_{t}\left[\left(C+D x_{t}^{*}\right)^{\prime} \zeta_{\tau} \zeta_{\tau}^{\prime}\left(C+D x_{t}^{*}\right)\right]
$$


In the Appendix A, we provide a detailed derivation of all the elements in $\zeta_{\tau} \zeta_{\tau}^{\prime}$, the block matrix whose expected value delivers the variances of and covariances between the shocks that drive unexpected inflation (and thus uncertainty).

As it will become clear later, having a survey-based measure of inflation uncertainty allows us to better pin down some of the parameters in $C$ and $\zeta_{\tau}$. More importantly, the vector of parameters $\omega_{1}$ can be identified only if we incorporate survey data on this second moment.

\subsection{Inflation Risk Premium}

We now turn to the main object of interest in this study, that is, the IRP, which is defined as follows:

$$
\begin{aligned}
I R P_{t}= & r_{t}^{N}-r_{t}^{R}-\pi_{t}=-\left(\lambda_{0}^{N \prime} \lambda_{0}^{q}+\frac{1}{2} \lambda_{0}^{q \prime} \lambda_{0}^{q}-\frac{1}{2} \omega_{0}^{2}\right)+ \\
& -\left(\Lambda^{q \prime} \lambda_{0}^{N}+\Lambda^{N \prime} \lambda_{0}^{q}-\Lambda^{q \prime} \lambda_{0}^{q}-\omega_{0} \omega_{1}\right)^{\prime} x_{t}^{*}+ \\
& -x_{t}^{* \prime}\left(\Lambda^{N \prime} \Lambda^{q}-\frac{1}{2} \Lambda^{q \prime} \Lambda^{q}-\frac{1}{2} \omega_{1} \omega_{1}^{\prime}\right) x_{t}^{*}
\end{aligned}
$$

Our IRP has a richer dynamic behavior than permitted by previous studies in the literature, for example, Chernov and Mueller (2012) and D'Amico, Kim and Wei (2016), who already allowed for quite flexible dynamics. Particularly, in D'Amico, Kim and Wei (2016), the IRP is linear in the state variables and is time varying because of the state-dependent market price of nominal risk-i.e., the time variation is obtained by having just the term $\Lambda^{N^{\prime}} \lambda_{0}^{q}$ different from zero in the expression above.

In this model, the resulting specification of the IRP has two additional sources of flexibility. First, as shown in the last term of the above equation, it is a quadratic function of the state variables because of $\Lambda^{q}$ and $\omega_{1}$. Second, the linear portion can vary because either the market price of nominal risk or the market price of inflation risk changes over time, as $\Lambda^{N}, \Lambda^{q}$, and $\omega_{1}$ multiply $x_{t}^{*}$.

This extremely adaptable functional form should allow our model to accommodate very different dynamic behaviors of the IRP over a long and diverse sample period including the inflation scare episodes of the 1980s when, in principle, perceptions of heightened inflation risk would have commanded large and positive values of the IRP, and the deflation scare episode of 2009-2012, when disinflation and low growth made nominal bonds a very good hedge against adverse outcomes possibly pushing the IRP into negative territory.

To provide a simple intuition for why the data on real-time inflation variance can improve the estimation of the IRP, we rewrite the IRP in the following way: 


$$
\begin{aligned}
I P R_{t, \tau} & =-\frac{1}{\tau} \log \left[1+\frac{\operatorname{Cov}\left(\frac{M_{t+\tau}^{R}}{M_{t}^{R}}, \frac{Q_{t}}{Q_{t+\tau}}\right)}{E_{t}\left(\frac{M_{t+\tau}^{R}}{M_{t}^{R}}\right) E_{t}\left(\frac{Q_{t}}{Q_{t+\tau}}\right)}\right]+J_{t, \tau} \\
& \approx-\frac{1}{\tau} \log \left[1+\operatorname{Cov}\left(r_{t, \tau}^{R}, i_{t, \tau}\right) / E_{t}\left(r_{t, \tau}^{R}\right) E_{t}\left(i_{t, \tau}\right)\right] \\
& =-\frac{1}{\tau} \log \left[1+\left(\operatorname{Cov}\left(r_{t, \tau}^{N}, i_{t, \tau}\right)-\operatorname{var}\left(i_{t, \tau}\right)\right) / E_{t}\left(r_{t, \tau}^{R}\right) E_{t}\left(i_{t, \tau}\right)\right] .
\end{aligned}
$$

where for simplicity we are assuming that the real pricing kernel is mainly driven by the real yield and we are ignoring the Jensen's inequality term, which in practice is fairly small. ${ }^{2}$

Based on this simplification, it is easy to see that to the extent that variations in the covariance between the real economy and inflation arises from fluctuations in the variance of inflation, accurate measurement of these specific fluctuations would be important. Survey data on real-time inflation uncertainty serve this purpose, that is, they help identifying fluctuations in the variance of inflation and thus in the time-varying IRP. Further, as we will explain shortly in Section 4.1 where we describe the covariances of the state variables, having a time-varying market price on inflation risk $\lambda_{t}^{q}$ also allows time variation in the covariance between nominal interest rates and inflation, thus having more data to pin down $\lambda_{t}^{q}$ also helps in the estimation of that covariance.

\section{Comparison to previous studies}

This paper draws on contributions from several streams of the term-structural literature. First of all, to achieve time-varying second moments, we favor the use of Quadratic Gaussian (QG) models because affine term-structure models with stochastic volatility typically fail to produce reasonable risk premia (Dai and Singleton, 2002 and Duffee, 2002) and fitted yield volatilities that resemble the time-varying volatilities estimated from semi-parametric time-series models (Ahn, Dittmar, and Gallant, 2002; Collin-Dufresne, Goldstein, and Jones, 2009). For example, Haubrich, Pennacchi, and Ritchken (2012) develop a completely affine model that has four stochastic drivers and seven factors, but it still generates IRP that do not seem very sensible up to the two-year horizon, as it is mostly negative even in the early 1980s, when most other studies find that IRP estimates reach their highest peak.

In contrast, as shown in Kim (2004), QG models do not seem to exhibit a tradeoff between fitting yield volatility and risk premia, therefore, we build on these type of models (e.g., Kim, 2004; and Kim and Singleton, 2012) and expand on them

\footnotetext{
${ }^{2} J_{t, \tau} \equiv-\left(\frac{1}{\tau}\right)\left[\log \left(E_{t}\left(Q_{t} / Q_{t, \tau}\right)\right)-E_{t}\left(\log \left(Q_{t} / Q_{t, \tau}\right)\right)\right]$.
} 
by adding flexibility to market prices of inflation risk and allowing for unspanned inflation risk. Particularly, we decided to expand in this direction because Le and Singleton (2013) show that substantial variation in risk premia is unspanned by nominal bond yields and seems to arise from a time-varying market price of inflation risk; and, D'Amico and Orphanides (2014) show that perceived inflation risk is an important driver of excess bond returns beyond and above the information contained in nominal yields.

To allow for unspanned inflation risk, our model includes some of the unspanning restrictions emphasized in Duffee (2011) and Joslin, Priebsch, and Singleton (2014), and similarly to the latter, we also run preliminary regressions to motivate our hidden factor. Table 1 reports the percentage of variation $\left(R^{2}\right)$ in inflation related variables explained by the 3 latent factors of an affine term-structure model estimated using only nominal yields and short-term rate forecasts. We find that although more than $80 \%$ of variation in expected inflation is explained by these factors, only half of the variation in inflation uncertainty is explained by those same factors. In line with this observation, our unspanning restrictions permit our third factor to drive both expected inflation and inflation uncertainty while remaining hidden from the nominal yield curve.

Our paper is also closely related to studies emphasizing the size and nature of the IRP. For example, similarly to Chernov and Mueller (2012), we use surveybased inflation expectations at various horizons, but while their preferred model uses TIPS yields in the estimation, we use short- and long-horizon survey forecasts of nominal interest rates that together with surveys forecasts of inflation help to pin down the term-structure of expected real rates over a longer sample. A more important difference is that in this paper, we focus on modeling time variation in the market price of inflation risk and incorporate information from survey-based inflation variance, which in turn permits us to identify a more flexible dynamic of the IRP. Another relevant study that, however, uses a quite different approach is Buraschi and Jiltsov (2005). Specifically, these authors develop a structural model that can identify the underlying nominal and real factors driving the IRP, but also suffers from the shortcoming that the market price of risk, even if state dependent, is not as flexible as ours, which is based on a more reduced-form approach. Further, their dataset consists only of interest rates, CPI, and money supply, and thus does not include any information from survey forecasts. In addition, differently from our work, in both of these studies, the sample period stops before 2008.

Finally, our study is also related to equilibrium term-structure models implying that time-variation in expected excess returns of nominal risk-free bonds is driven by changes in variances of real and inflation risks (e.g., Bansal and Shaliastovich, 2012); however, in most of these models, the market price of risk is assumed to be constant and macro risk is fully spanned by nominal yields. This is also true for Campbell, Sunderam, and Viceira (2016), who assume that all time variation in bond risk premia is driven by variation in bond risk and not by variation in the 
aggregate price of risk. Importantly, their estimates of the variables governing bond risk are informed by realized second moments of high-frequency returns, while our estimates are informed by a real-time measure of perceived inflation risk. Moreover, we are more focused on modeling and estimating the IRP, while they emphasize the importance of the time-varying stock-bond covariance for the term structure of interest rates.

\section{State-space form and data}

In this section, we first present the state equation and emphasize the role of timevarying market prices of inflation risk in generating time variation in the covariances of the state variables, then we turn to the observation equations and highlight how they link the data to our state variables.

\subsection{State variables and their covariances}

We rewrite the model in a state-space form and estimate it by quasi maximum likelihood (QML) using the Augmented State Space Extended Kalman Filter method developed in Kim (2004). The basic idea of his approach is to augment the state vector $s_{t}$ with the quadratic term vech $\left(x_{t}^{*} x_{t}^{* \prime}\right), s_{t}=\left[x_{t}^{*} \text {, vech }\left(x_{t}^{*} x_{t}^{* \prime}\right), q_{t}\right]^{\prime}$, such that the state equations can be written in the usual linear matrix form:

$$
s_{t}=G_{h}+\Gamma_{h} s_{t-h}+\eta_{t}^{s},
$$

where $\eta_{t}^{s}=\left[\Sigma \eta_{t}, v_{t}, \lambda^{q}\left(x_{t-h}^{*}\right)^{\prime} \eta_{t}+\omega\left(x_{t-h}^{*}\right)^{\prime} \eta_{t}^{\perp}\right]$ is the vector of innovations to $x_{t}^{*}$, $\operatorname{vech}\left(x_{t}^{*} x_{t}^{* \prime}\right)$, and $q_{t}$, respectively, and $v_{t}, G_{h}$ and $\Gamma_{h}$ are defined in the Appendix B. The conditional variance of the state variables, $\Omega_{t-h}^{s}=\operatorname{Var}\left(s_{t} \mid I_{t-h}\right)=E_{t-h}\left(\eta_{t}^{s} \eta_{t}^{s}\right)$, is given by:

$$
\begin{gathered}
E\left[\begin{array}{ccc}
\Sigma \eta_{t} \eta_{t}^{\prime} \Sigma^{\prime} & \Sigma \eta_{t} v_{t}^{\prime} & \Sigma \eta_{t} \eta_{t}^{\prime} \lambda^{q}\left(x_{t-h}^{*}\right)^{\prime} \\
v_{t} \eta_{t}^{\prime} \Sigma^{\prime} & v_{t} v_{t}^{\prime} & v_{t} \eta_{t}^{\prime} \lambda^{q}\left(x_{t-h}^{*}\right)^{\prime} \\
\lambda^{q}\left(x_{t-h}^{*}\right) \eta_{t} \eta_{t}^{\prime} \Sigma^{\prime} & \lambda^{q}\left(x_{t-h}^{*}\right) \eta_{t} v_{t}^{\prime} & \lambda^{q}\left(x_{t-h}^{*}\right) \eta_{t} \eta_{t}^{\prime} \lambda^{q}\left(x_{t-h}^{*}\right)^{\prime}+\omega\left(x_{t-h}^{*}\right)^{2} \eta_{t}^{\perp 2}
\end{array}\right]= \\
{\left[\begin{array}{ccc}
\operatorname{Var}_{t-h}\left(x_{t}^{*}\right) & \operatorname{Cov}_{t-h}\left(x_{t}^{*}, \operatorname{vech}\left(x_{t}^{*} x_{t}^{* \prime}\right)\right) & \operatorname{Cov}_{t-h}\left(x_{t}^{*}, q_{t}\right) \\
\operatorname{Cov}_{t-h}\left(x_{t}^{*}, \operatorname{vech}\left(x_{t}^{*} x_{t}^{* \prime}\right)\right) & \operatorname{Var}_{t-h}\left(\operatorname{vech}\left(x_{t}^{*} x_{t}^{* \prime}\right)\right) & \operatorname{Cov}_{t-h}\left(\operatorname{vech}^{\prime}\left(x_{t}^{*} x_{t}^{* \prime}\right), q_{t}\right) \\
\operatorname{Cov}_{t-h}\left(x_{t}^{*}, q_{t}\right) & \operatorname{Cov}_{t-h}\left(\operatorname{vech}\left(x_{t}^{*} x_{t}^{* \prime}\right), q_{t}\right) & \operatorname{Var}_{t-h}\left(q_{t}\right)
\end{array}\right]}
\end{gathered}
$$

It is worth noting the different roles played by $\lambda^{q}\left(x_{t}^{*}\right)$ and $\omega\left(x_{t}^{*}\right): \lambda^{q}\left(x_{t}^{*}\right)$ allows covariances between all latent factors and the log price level $q_{t}$ to be time-varying and also contributes to the time variation in the variance of $q_{t}$; in contrast, $\omega\left(x_{t}^{*}\right)$ governs only the variance of $q_{t}$. This suggests that, in principle, the estimated values of $\omega\left(x_{t}^{*}\right)$ should be strongly influenced by data on inflation uncertainty, which will also help identifying fluctuations in the variable $\lambda^{q}\left(x_{t}^{*}\right)$. 


\subsection{Observation equations and data}

From January 1983 to December 2013, we observe seven nominal yields $Y_{t}^{N}=$ $\left\{y_{t, \tau_{i}}^{N}\right\}_{i=1}^{7}$, the 6-month, 12-month, and 6-to-11 years ahead forecasts of the nominal short rate $f_{t}^{6 m}, f_{t}^{12 m}$, and $f_{t}^{\text {long }}$ respectively, the survey inflation expectations at one- and 11-year horizons $E I_{t}^{1 y}$ and $E I_{t}^{11 y}$, as well as the one-year real-time inflation uncertainty $I U_{t}^{1 y}$. We collect all the observable variables in the vector $o_{t}=\left[Y_{t}^{N}, f_{t}^{6 m}, f_{t}^{12 m}, f_{t}^{\text {long }}, E I_{t}^{1 y}, E I_{t}^{11 y}, I U_{t}^{1 y}\right]^{\prime}$ and write also the observation equations in a matrix form:

$$
o_{t}=a+F s_{t}+\varepsilon_{t}
$$

where $\varepsilon_{t}$ denotes the vector of measurement errors, assumed to be i.i.d., with freely estimated variances: $\varepsilon_{t, \tau_{i}}^{Y^{N}} \sim N\left(0, \delta_{N, \tau_{i}}^{2}\right), \varepsilon_{t, \tau_{i}}^{f} \sim N\left(0, \delta_{f, \tau_{i}}^{2}\right), \varepsilon_{t, \tau_{i}}^{E I} \sim N\left(0, \delta_{E I, \tau_{i}}^{2}\right)$, and $\varepsilon_{t}^{I U} \sim N\left(0, \delta_{I U}^{2}\right)$

More details about the functional form of the observation equations and thus of $a$ and $F$ are provided in Appendix C. However, we stress here how each observation equation links specific data to all or some of the state variables. Further, it should be noted that inflation and survey-based variables are not available for all dates, which introduces missing data in the observation equation and are handled in the standard way by allowing the dimensions of $a$ and $F$ to be time-dependent (see, for example, Harvey 1989).

The first seven measurement equations relate observable Treasury nominal yields only to the two state variables $x_{t}$, due to the unspanning restrictions. Specifically, we use the 3- and 6-month Treasury bill rates from the Federal Reserve Board's H.15 release and converted them to continuously compounded basis. The 1-, 2-, 4-, 7-, and 10-year nominal yields are based on zero-coupon yield curves fitted at the Federal Reserve Board (see Gurkaynak, Sack, and Wright, 2007; Gurkaynak, Sack, and Wright, 2010 for details). We sample yields at the weekly frequency and assume that the monthly CPI-U data is observed on the last week of the current month. ${ }^{34}$

Similarly, our eighth and ninth measurement equations also link the 6- and 12month-ahead forecasts of the 3-month Treasury bill rate from Blue Chip Financial Forecasts $(\mathrm{BCFF})$, which are available monthly, only to $x_{t}$. We complement these measurement equations with another one that uses the long-range forecast (6-to-11 years ahead) of the same rate. In BCFF, this forecast is provided only semiannually, but we follow the procedure in D'Amico and King (2015) to convert them to a consistent quarterly frequency, as we think that information from longer-term survey forecasts is very important to correctly estimate the persistency of the yield factors under the physical measure. The basic idea consists of combining the long-range

\footnotetext{
${ }^{3}$ Here we abstract from the real-time data issue by assuming that investors correctly infer the current inflation rate in a timely fashion.

${ }^{4}$ The data source for the nominal yields and CPI-U is Haver.
} 
forecasts from BCFF with those from Blue Chip Economic Indicators (BCEI). This is because BCFF provide these long-range projections in June and December, while the BCEI report them in March and October, these values can then be interpolated to obtain the September value and have a regularly-spaced quarterly time series. ${ }^{5}$

The eleventh and twelfth equations relate the observed measures of expected inflation at the 1- and 11-year horizon to all state variables $x_{t}^{*}$, as inflation-related variable are allowed to load on the hidden factor. Specifically, we use the median forecast of average inflation over the following year from the Survey of Professional Forecasters (SPF) because it is reported at a consistent quarterly frequency and therefore does not require interpolation. However, since the longest available forecasting horizon in these data is one-year ahead, to measure longer-term inflation expectations we turn again to the BCS, which has been providing semiannual longrange (2-to-6 and 7-to-11 years ahead) consensus forecasts of CPI since 1983. Once we have converted them to a consistent quarterly frequency using the same methodology described for interest rate forecasts, we can compute the expected average value over the next 11 years - by taking the weighted average of the one-year, 2-6year, and 7-11-year expectations, respectively.

Finally, the last observation equation relates the real-time measure of inflation variance at one-year horizon to all state variables $x_{t}^{*}$ as well as to vech $\left(x_{t}^{*} x_{t}^{* \prime}\right)$. The real-time measure of inflation variance is derived from the subjective probability distributions in the SPF using the methodology of D'Amico and Orphanides (2008), therefore it should capture ex-ante inflation risk perceived by investors rather than ex-post realized volatility.

\section{Identification and estimation methodology}

Except for the unspanning restrictions already described in Section 2.1, for all other parameters in the model, we only impose restrictions that are necessary for achieving identification to allow a maximally flexible correlation structure between the factors, which has shown to be critical in fitting the rich behavior of risk premia observed in the data. In particular:

$$
\mu=0_{3 \times 1}, \kappa=\left[\begin{array}{ccc}
\kappa_{11} & 0 & 0 \\
0 & \kappa_{22} & 0 \\
0 & 0 & \kappa_{33}
\end{array}\right], \Sigma=\left[\begin{array}{ccc}
1 & 0 & 0 \\
\Sigma_{21} & 1 & 0 \\
\Sigma_{31} & \Sigma_{32} & 1
\end{array}\right]
$$

and $\Lambda^{N}$ is unrestricted.

Regarding the set of parameters that allow for time variation in the variance of inflation and covariances of inflation with the other state variables, we have that $\Lambda^{q}$ is lower triangular and $\omega_{1}$ is left unrestricted:

\footnotetext{
${ }^{5}$ For more details see the Appendix in D'Amico and King (2015).
} 


$$
\Lambda^{q}=\left[\begin{array}{ccc}
\Lambda_{11}^{q} & 0 & 0 \\
\Lambda_{21}^{q} & \Lambda_{22}^{q} & 0 \\
\Lambda_{31}^{q} & \Lambda_{32}^{q} & \Lambda_{33}^{q}
\end{array}\right] \text { and } \omega_{1=}\left[\begin{array}{lll}
\omega_{11} & \omega_{12} & \omega_{13}
\end{array}\right]
$$

This implies that the market price of inflation risk can be affected by all three factors $x_{t}^{*}$ and their interactions, and that the conditional volatility of the shock specific to CPI is also affected by the same three factors $x_{t}^{*}$.

To facilitate the estimation by starting with reasonable initial values of the parameters and to make the results easily replicable, we break the estimation in a few easier steps: We first perform a "pre"-estimation where a set of preliminary parameter estimates governing the nominal term structure is obtained using $Y_{t}^{N}$ and survey forecasts of 3-month TBill rate alone, ${ }^{6}$ second, based on these estimates and data on $Y_{t}^{N}$, we can obtain a preliminary estimate of the state variables, $x_{t}$ and $d B_{t}$; third, a regression of monthly inflation onto estimates of $x_{t}$ and $d B_{t}$ gives preliminary estimates of $\rho_{0}^{\pi}, \rho_{1}^{\pi}, \lambda_{0}^{q}, \Lambda^{q}, \omega_{0}$; fourth, a regression of quarterly inflation uncertainty on $x_{t}$ and $x_{t}^{2}$ gives preliminary estimates of $\omega_{1}$; and finally, these preliminary estimates are used as starting values in the full, one-step estimation of all model parameters by QML.

\section{Empirical Findings}

In this section, we first provide a summary description of the results based on our "full" model specification, which includes all the features described above and incorporates in the estimation all the information from surveys. Then, we dissect the results to highlight the contribution of key elements of our approach separately, by presenting comparisons with simpler specifications and with the estimation that does not make use of survey information on the second moment of inflation.

\subsection{Full model specification}

A visual description of our main findings is presented in Figures 1, 2, and 3. Specifically, Figure 1 shows the decomposition of the 10-year nominal yield into three components: The real yield (including the RRP), the expected inflation at the pertinent horizon, and the corresponding IRP. Figure 2 focuses on the four components of the 10-year nominal yield, as in addition to the expected inflation rate and IRP (also shown in Figure 1), it shows the expected future short real rate and the RRP separately. Finally, Figure 3 summarizes the overall fit of the full model, as it compares the model-implied one-year inflation variance, 5-year real yield, one-year

\footnotetext{
${ }^{6}$ It is important to keep in mind that in this preliminary estimation we do not impose unspanning and therefore derive 3 latent factors from the nominal term structure. This implies that especially the third factor will have a dynamic quite different from that one of the hidden factor obtained in the final step of the estimation.
} 
expected inflation, and one-year expectation of the nominal short-term rate to their counterparts in the data (shown in orange).

As it can be seen in Figure 1, the model estimation over the 1983 to 2013 period captures the main characteristics of the time variations in longer-term nominal yields that have been discussed in the earlier literature. Overall, inflation expectations, real interest rate expectations, the IRP as well as the RRP all trended down during the 1980s and 1990s. Real yields dominate the other components in accounting for the fluctuations in nominal yields. However, the major sources of variation differ at low and high frequencies. While the expectation component of the yield - the expected real interest rate and expected inflation - dominate at business cycle frequencies, the risk premia largely drive higher-frequency fluctuations.

Focusing on the estimates of the 10-year IRP in Figure 2, our findings suggest that it was consistently positive in the first part of the sample, reaching its highest peak (about 1.7 percentage points) in the spring of 1984, and then spiked again in May-October 1987. Since the mid 1990s, it has fluctuated around zero, reaching its most negative values (about -0.6 percentage points) in 2005-2007, just before the most recent financial crisis, and during the subsequent weak recovery, in 2011-2012.

The largest fluctuations in the estimated IRP capture notable episodes documented over this period that reflected changes in perceptions of inflation risks. The spikes in 1984 and 1987, for example, coincide with the narrative of the inflation scares of the 1980s documented by Goodfriend (1993). Similarly, the substantial decline over the 2010-2012 period largely coincides with the deflation scare episode described in Kitsul and Wright (2013). Our estimates of the IRP also capture episodes that have occupied discussions relating to monetary policy. One notable example is the "conundrum" period in the mid-2000s when, as shown in Figure 2, risk premia started declining sharply in 2004 while the Federal Reserve was raising short-term nominal interest rates. Another example is the "taper-tantrum" in the summer of 2013, when longer-term Treasury yields rose dramatically following Fed Chairman Ben Bernanke's remarks about the possibility of moderating the pace of asset purchases later that year, implying a lower degree of expected monetary policy accommodation.

Interestingly, our findings also illustrate the time-varying nature of the covariance of yield components. While in much of the 1980s, all four components broadly move in the same direction, after 1987 expectations and risk premia start moving in opposite directions. This pattern is particularly evident in 1987-1992, 2001-02, 2004-08, and 2011-2013. These are periods highlighting the presence of a hidden factor: Changes in the hidden factor would move the IRP and RRP in the same amount of but opposite to the expected future short real rates and the expected inflation. This could explain the conundrum period and also indicates that the entire increase in the nominal yields observed during the taper tantrum was indeed due to increases in risk premia.

Turning attention to the expected inflation and expected short-term real interest 
rates, Figure 2 also shows that the model captures their secular decline since the 1980s. With respect to inflation expectations, this decline is consistent with the Federal Reserve's successful disinflation efforts over the 1980s and 1990s and its strategy of maintaining mostly stable inflation since then. With respect to the decline in long-term expectations of the short-term real interest rate, the model's findings are consistent with studies suggesting a notable decline in the equilibrium real interest rate over this period (Holtson, Laubach and Williams, 2016).

Moving to the overall fit of the full model, Figure 3 suggests that the modelimplied variables match their data counterparts quite well. Starting from the top left panel, it can be noted that the fluctuations in the model-implied one-year inflation variance track quite closely those in the survey-based inflation variance. Further, despite being estimated without the use of TIPS yields, as shown in the top right panel, the full model generates a 5-year real yield that closely resembles that one on TIPS (when available), except for a residual very similar to the liquidity premium estimated in D'Amico, Kim, and Wei (2016). In their study, the estimated TIPS liquidity premium is fairly high and positive in the early years of TIPS, then declines steadily and stays close to zero from 2004 until the height of the 2007-08 financial crisis, when it surges to its highest level, to then turn negative around 2011. The two bottom panels indicate that the model can match pretty well one-year survey forecasts of inflation and of the short-term rate. This also illustrates that the survey information about first moments of key variables like inflation and the short rate help the model capturing the slow moving trend in those expectations as well as the ZLB period.

\subsection{Dissecting the model's key features}

The main empirical contributions of our study can be more easily illustrated and understood by comparing the empirical performance of the full model to the results derived from different model specifications, with each specification obtained by removing from the full model one of its key ingredients. We consider three simplifications: 1) the model without time-varying inflation volatility, called Model No_TVV (No time-varying volatility, i.e., $\omega_{1}=0_{3 \times 1}$ and $\Lambda^{q}=0_{3 \times 3}$ ); 2) the model estimated without data on inflation uncertainty (called No_IU) and thus without $\omega_{1}$, which cannot be correctly identified without those data; and 3) the model estimated letting also $z_{t}$ to be spanned by nominal yields, called No_Unsp (No unspanning, i.e.,

$\rho_{1}^{N}(3)$ unrestricted and $\Lambda^{N}$ a $3 \times 3$ unrestricted matrix). Table 2 summarizes those model specifications and associated parameters restrictions.

The first exercise quantifies the contribution of time-varying market prices of inflation risk to the overall model performance. The second exercise aims at understanding the value added by survey information about perceived inflation uncertainty, and as a consequence the role played by the time-varying conditional volatility of the orthogonal shock specific to CPI, which should capture high-frequency 
variations in inflation. Finally, the third experiment is meant to shed light on the importance of the hidden factor for capturing variations in the first and second moments of inflation.

Figure 4 summarizes the comparison between the model with homoskedastic inflation shocks (Model No_TVV), whose results are plotted in the left panels, and the full model, whose results are plotted in the right panels. For each model, we show in blue the estimated values of the one-year inflation variance, the two-year IRP, the 5-year real yield, and the one-year expected inflation, and in orange their data counterparts. For brevity, we do not report the estimates for longer-term variables as they provide the same message and, for the full model, have been highlighted in the Figure 1 and 2.

The panel's first row shows the implications of restricting the model to homoskedastic inflation shocks. While the full model is able to match quite closely the fluctuations in the survey-based inflation variance, the Model No_TVV estimates the inflation variance to be constant at 0.8 percent which is too low to capture the 1980 s and too high to capture the more recent period of relative stability. As shown in the second and third rows, this has important implications for the estimated IRP and real yields. The homoskedastic model generates IRP estimates that are implausible: They are extremely large (in absolute value), as they vary between -10 and +11 percent, and are trending upward over the sample period, with the lowest values in the early 1980s and the highest peak in 2013. In contrast, the full model estimates the 2-year IRP to reach its highest value of about 50 basis points in the early 1980s, then to decline quite consistently through the mid 1990s when it turns negative, particularly in 2001-02, 2004-06, and 2010-12, but also to increase sharply at the height of the recent financial crisis in 2008-09 and in the summer of 2013 during the so-called taper tantrum. As shown in the third row, the 5-year real yield implied by Model No_TVV also fluctuates within an unreasonable range, as it reaches almost 20 percent in the early 1980s and about - 15 percent in 2012; while, on the other hand, the full model generates a 5-year real yield that reaches at most about 7 percent in the early 1980s and closely resembles that one on TIPS (when available), as already noted in the discussion of Figure 3. However, the homoskedastic model fits the one-year survey expected inflation slightly better, indicating that, if survey forecasts of inflation are used in the estimation, having time-varying inflation volatility does not add much along this dimension. This may be due to the hidden factor, which is responsible solely for variations in inflation-related variables. Since the hidden factor has to capture only fluctuations in inflation expectations but not in the inflation variance, it is possible that it is doing a much better job in fitting the survey-based first moments.

The next four figures compare results from the full model to the other two simplifications we consider, that is, Model No_IU and Model No_Unsp. Figure 5 shows the estimates of the IRP at 2- and 10-year maturity and of the one-year inflation variance together with the SPF counterpart across the three model specifications. 
Looking at the third column, it is evident that only the full model is successful in capturing the fluctuations in the survey-based inflation variance. Of course, this is not that surprising relative to the model estimated without data on inflation uncertainty, but is interesting to note the deterioration in the fit when the data on inflation uncertainty is used in the estimation of the model without unspanning. Indeed, as illustrated by the contrast between the top and bottom right panels, it seems that allowing for a factor that does not influence nominal interest rates but does influence inflation-related variables is important to capture fluctuations in perceived inflation risk. The regression analysis reported in Table 3 confirms this observation. The table shows the $R^{2}$ from regressions of the inflation-related concepts onto the three factors implied by the full model. As shown in the last column of the table, the hidden factor explains a large portion of variations in the surveybased inflation variance that is not explained by the other two factors: Including the hidden factor in the regression raises the $R^{2}$ from $47 \%$ to $83 \%$. In turn, since Model No_IU and Model No_Unsp do not fit inflation variance well, they do not generate very sensible IRP especially in the 1980s. For the Model No_IU, the estimated 2 -year IRP is implausibly small and even negative in the early 1980s. This is not consistent with most estimates available in the literature, which tend to be sizable and positive across maturities during those years. In contrast, Model No_Unsp estimates values of the IRP that are as high as 7.3 percent in the early $1980 \mathrm{~s}$ and are always positive, which is implausibly high. Indeed, most studies obtain estimates of the IRP that hardly reach 2 percent, even at longer maturities, and often turn negative starting in the 2000s (e.g., Buraschi and Jiltsov, 2005; Chernov and Mueller, 2012; Haubrich et al. 2012, Ajello et al., 2012). Based on those previous findings, it seems that the estimated IRP from the full model, reported in the left and middle top panels, is much more sensible. In addition to the dynamic behavior of the IRP already described in Figure 2, it is worth noting that the average term structure of the IRP is upward sloping, as it is usually more difficult to predict inflation at longer horizons and thus uncertainty about inflation is larger. Further, the greater duration of longer-term bonds amplifies the impact of a given amount of inflation uncertainty.

Figure 6 illustrates the implications of the IRP estimates for the model-implied real yields and RRP. The bottom row shows quite starkly that, in the case of the Model No_Unsp, the flip side of extremely large and positive IRP is extremely low and flat real yields and RRP, which at the 10-year horizon reaches -1 percent in 1984. To a much lesser extent there is a similar trade-off also in the case of the Model No_IU, but only in the early 1980s, which at the 10-year maturity is less evident than at the 2-year maturity (not shown for brevity). In particular, since in the absence of survey data on inflation uncertainty, this model produces IRP that are too low or even negative in the early 1980s, it generates real yields and RRP that seem a bit too high in the same period, with the 2-year real yield as high as the 10-year real yield, and the 2-year RRP reaching a peak of about 2 percent in 1984 to 
counterbalance the negative values of the IRP in the same period. Finally, the full model, similarly to the results for the 5-year real yield already described in Figure 3 , generates a 10-year real yield that closely resembles that one on TIPS, again except for a residual very similar to the 10-year TIPS liquidity premium estimated in D'Amico, Kim, and Wei (2016). This model also delivers a 10-year RRP that is mostly positive over the sample period, displaying a marked downward trend as it declines from a level of about 3.5 percent in the early 1980 s to almost 0.5 percent at the end of 2013.

Figure 7 makes a very simple point: the fit of survey inflation expectations across the three models is very similar. This suggests that the data on inflation variance and the hidden factor have almost no effect on the model-implied estimates of inflation expectations at short and long horizons, when their survey counterparts are included in the estimation. It also implies that these estimates are mainly governed by the two latent factors that extract information mostly from nominal yields and the survey forecasts of the short-term rate. Table 3 confirms this observation: $R^{2}$ from regressions of the inflation-related concepts onto the first two factors (the yield factors) are as high as 84 percent, and the $R^{2}$ does not increase much once we include the hidden factor in the regression specification. Using long-range survey forecasts of the short-term interest rate in the estimation produces a level yield factor that is quite persistent and is therefore able to capture the gradual downward trend in inflation expectations.

Finally, figure 8 clearly illustrates that also the fit of survey forecasts of the nominal short-term rate, at short and long horizons, is very similar across the three models. This, together with the evidence presented in Figure 7, in turn, suggests that expected real rates are well pinned down simply by the difference between survey forecasts of nominal interest rates and inflation. Thus, if a term-structure model allows for a flexible specification of the IRP, whose richer dynamics are better identified using survey information on inflation variance, as it is the case in the full model, then the difference between the observed nominal yields and the sum of expected real rates, expected inflation and IRP (all of which are extracting information from survey data), will be sufficient to inform the estimates of the RRP. This is the basic intuition to understand the ability of the full model to generate more sensible IRP and RRP over this long sample period.

Finally, it is also worth observing that, since all the models fit survey forecasts of the short-term rate very closely, even during the ZLB period, and since these forecasts do not violate the ZLB, then also the model-implied estimates of nominal short rates obey the ZLB at these maturities. In other words, information from surveys is extremely helpful for the estimation of our model also at the ZLB. 


\section{Concluding remarks}

We show that a Quadratic-Gaussian model of the term structure resulting from a flexible specification of the market prices of inflation risk and estimated using surveybased inflation uncertainty can capture the rich dynamics of inflation and real risk premia over the 1983-2013 period. It can also provide guidance on expected real interest rates and expected inflation embedded in longer-term yields.

In addition to a very flexible market price of inflation risk, two other features of the model appear particularly useful to capture correctly the dynamics of the inflation risk premia over time in our long sample. First, the introduction of timevarying volatility of the shock specific to CPI, which mainly captures short-run inflation fluctuations. Second, the presence of a hidden factor, which is supposed to govern the component of the inflation-related variables not spanned by nominal yields. Both of these elements improve the reliability of the estimated inflation risk and associated premium, and thus of the decomposition of nominal yields. Interestingly, our results suggest that the hidden factor is important mainly for the inflation variance. In contrast, inflation expectations load mostly on the level-yield factor, the most persistent state variable implied by our model.

With regard to the key novelty in the estimation, the use of real-time data on inflation uncertainty proves crucial for pinning down the dynamics of the inflation risk premium over our sample that includes both the 1980s, when perceived inflation uncertainty was high, and the 2000s and 2010s, when perceived inflation uncertainty was low. Use of this information would be much less important if attention were restricted to the more recent period of greater inflation stability.

The estimated model captures both the decline in inflation expectations from the 1980 s to the 2000s that is associated with the Federal Reserve's disinflationary efforts and the notable decline in the equilibrium real interest rate, as measured by the long-term expectations of the short-term real interest rate. A decomposition of the 10-year nominal yield suggests that the expectation components - the expected real interest rate and expected inflation - dominate at business cycle frequencies, while the risk premia largely drive higher-frequency fluctuations. Focusing on the IRP, the results confirm that it was considerably higher in the 1980s than over later periods. The estimates also identify episodes of notably negative IRP, such as the 20052007 period, just before the most recent financial crisis, and during the subsequent weak recovery, in 2011-2012. Overall, incorporating available survey information regarding first and second moments, allows for the estimation of a flexible term structure model that can capture the rich dynamics of risk premia and expectations. 


\section{Appendix A: Components of the inflation vari- ance}

For the interested reader we provide details on the inflation variance computation:

$$
\operatorname{Var}_{t}\left(i_{t, \tau}\right)=E_{t}\left[\frac{1}{\tau^{2}}\left(C+D x_{t}^{*}\right)^{\prime} \zeta_{\tau} \zeta_{\tau}^{\prime}\left(C+D x_{t}^{*}\right)\right]=\frac{1}{\tau^{2}}\left(C+D x_{t}^{*}\right)^{\prime} V_{\tau}\left(C+D x_{t}^{*}\right)
$$

where

$$
V_{\tau}=\left[\begin{array}{ccccccc}
V_{a a} & V_{a b} & V_{a c} & 0_{n \times 1} & 0_{n \times 1} & 0_{n \times n} & 0_{n \times 1} \\
V_{a b}^{\prime} & V_{b b} & V_{b c} & 0_{n \times 1} & 0_{n \times 1} & 0_{n \times n} & 0_{n \times 1} \\
V_{a c}^{\prime} & V_{b c}^{\prime} & V_{c c} & 0_{n \times 1} & 0_{n \times 1} & 0_{n \times n} & 0_{n \times 1} \\
0_{1 \times n} & 0_{1 \times n} & 0_{1 \times n} & V_{d d} & 0 & 0_{n \times n} & 0 \\
0_{1 \times n} & 0_{1 \times n} & 0_{1 \times n} & 0 & V_{e e} & V_{e f} & 0 \\
0_{n \times n} & 0_{n \times n} & 0_{n \times n} & 0_{n \times n} & V_{e f}^{\prime} & V_{f f} & 0_{n \times 1} \\
0_{1 \times n} & 0_{1 \times n} & 0_{1 \times n} & 0 & 0 & 0_{1 \times n} & V_{g g}
\end{array}\right]
$$

This can be written as:

$$
\operatorname{Var}_{t}\left(i_{t, \tau}\right)=a_{i u}+b_{i u} x_{t}^{*}+x_{t}^{* \prime} C_{i u} x_{t}^{*}
$$

where:

$$
\begin{aligned}
a_{i u} & =\frac{1}{\tau^{2}}\left[\rho_{1}^{\pi \prime}\left(V_{a a} \rho_{1}^{\pi}+V_{a b}\left(\lambda_{0}^{q}+\Lambda^{q} \mu\right)-V_{a c} \mu\right)+\left(\lambda_{0}^{q}+\Lambda^{q} \mu\right)^{\prime}\left(V_{a b}^{\prime} \rho_{1}^{\pi}\right.\right. \\
& \left.+V_{b b}\left(\lambda_{0}^{q}+\Lambda^{q} \mu\right)-V_{b c} \mu\right)-\mu^{\prime}\left(V_{a c}^{\prime} \rho_{1}^{\pi}+V_{b c}^{\prime}\left(\lambda_{0}^{q}+\Lambda^{q} \mu\right)-V_{c c} \mu\right)+V_{d d} \\
& \left.+\left(\omega_{0}+\omega_{1}^{\prime} \mu\right)^{\prime}\left(V_{e e}\left(\omega_{0}+\omega_{1}^{\prime} \mu\right)-V_{e f} \mu\right)-\mu\left(V_{e f}^{\prime}\left(\omega_{0}+\omega_{1}^{\prime} \mu\right)-V_{f f} \mu\right)+V_{g g}\right] \\
b_{i u} & =\frac{2}{\tau^{2}}\left[\rho_{1}^{\pi \prime} V_{a c}+\left(\lambda_{0}^{q}+\Lambda^{q} \mu\right)^{\prime} V_{b c}-\mu^{\prime} V_{c c}+\left(\omega_{0}+\omega_{1}^{\prime} \mu\right)^{\prime} V_{c f}-\mu^{\prime} V_{f f}\right] \\
c_{i u} & =\frac{1}{\tau^{2}}\left[V_{c c}+V_{f f}\right]
\end{aligned}
$$


with elements given by:

$$
\begin{aligned}
& V_{a a}=\kappa^{-1} \int_{0}^{\tau}\left(I_{n x n}-e^{-\kappa(\tau-s)}\right) \Sigma \Sigma^{\prime}\left(I_{n x n}-e^{-\kappa(\tau-s)}\right)^{\prime} \kappa^{-1 \prime} d s \\
& =\kappa^{-1} \int_{0}^{\tau} \Sigma \Sigma^{\prime}-\Sigma \Sigma^{\prime} e^{-\kappa(\tau-s) \prime}-e^{-\kappa(\tau-s)} \Sigma \Sigma^{\prime}+e^{-\kappa(\tau-s)} \Sigma \Sigma^{\prime} e^{-\kappa(\tau-s) \prime} d s \kappa^{-1 \prime} \\
& =\kappa^{-1}\left[\tau \Sigma \Sigma^{\prime}-\Sigma \Sigma^{\prime}\left(I_{n x n}-e^{-\kappa / \tau}\right) \kappa^{-1 \prime}-\kappa^{-1}\left(I_{n x n}-e^{-\kappa \tau}\right) \Sigma \Sigma^{\prime}+F_{0, \tau}\left(\kappa, \kappa^{\prime}, \Sigma \Sigma^{\prime}\right)\right] \kappa^{-1 \prime} \\
& V_{a b}=\kappa^{-1} \int_{0}^{\tau}\left(I_{n x n}-e^{-\kappa(\tau-s)}\right) \Sigma d s \\
& =\kappa^{-1}\left[\tau I_{n x n}-\kappa^{-1}\left(I_{n x n}-e^{-\kappa \tau}\right)\right] \Sigma \\
& V_{a c}=\kappa^{-1} \int_{0}^{\tau}\left(I_{n x n}-e^{-\kappa(\tau-s)}\right) \Sigma \Lambda^{q} e^{-\kappa s} d s \\
& =\kappa^{-1} \int_{0}^{\tau} \Sigma \Lambda^{q} e^{-\kappa s}-e^{-\kappa(\tau-s)} \Sigma \Lambda^{q} e^{-\kappa s} d s \\
& =\kappa^{-1}\left[\Sigma \Lambda^{q}\left(I_{n x n}-e^{-\kappa \tau}\right) \kappa^{-1}-e^{-\kappa \tau} F_{0, \tau}\left(-\kappa, \kappa, \Sigma \Lambda^{q}\right)\right] \\
& V_{b b}=\int_{0}^{\tau} I_{n x n} d s=\tau I_{n x n} \\
& V_{b c}=\int_{0}^{\tau} \Lambda^{q} e^{-\kappa s} d s=\Lambda^{q} \kappa^{-1}\left(I_{n x n}-e^{-\kappa \tau}\right) \\
& V_{c c}=\int_{0}^{\tau} e^{-\kappa s \prime} \Lambda^{q \prime} \Lambda^{q} e^{-\kappa s} d s=F_{0, \tau}\left(\kappa^{\prime}, \kappa, \Lambda^{q \prime}, \Lambda^{q}\right) \\
& V_{d d}=E_{t}\left[\int_{0}^{\tau} \xi_{s}^{\prime q^{\prime}} \Lambda^{q} \xi_{s} d s\right]=G_{0, \tau}\left(\Lambda^{q^{\prime}} \Lambda^{q}\right) \\
& V_{e e}=\int_{0}^{\tau} d s=\tau \\
& V_{e f}=\int_{0}^{\tau} \omega_{1}^{\prime-\kappa s} d s=\omega_{1}^{\prime-1}\left(I_{n \times n}-e^{-\kappa \tau}\right) \\
& V_{f f}=\int_{0}^{\tau} e^{-\kappa s \prime} \omega_{1} \omega_{1}^{\prime-\kappa s} d s=F_{0, \tau}\left(\kappa^{\prime}, \kappa, \omega_{1} \omega_{1}^{\prime}\right) \\
& V_{g g}=E_{t}\left[\int_{0}^{\tau} \xi_{s}^{\prime} \omega_{1} \omega_{1}^{\prime} \xi_{s} d s\right]=G_{0, \tau}\left(\omega_{1} \omega_{1}^{\prime}\right)
\end{aligned}
$$

\section{Appendix B: The discrete state equation}

To estimate the model, we need to discretize it and derive its state-space form. Let $h$ be a very small time interval, it follows that:

$$
x_{t}^{*}=\kappa \mu h+\left(I_{n x n}-\kappa h\right) x_{t-h}^{*}+\Sigma \eta_{t}=K+H x_{t-h}^{*}+\Sigma \eta_{t}
$$


where $\eta_{t} \sim N\left(0, h I_{n x n}\right)$. This means the discretized expression for the log price level is:

$$
q_{t}=q_{t-h}+\rho_{0}^{\pi} h+\rho_{1}^{\pi \prime} x_{t-h}^{*} h+\lambda^{q}\left(x_{t-h}^{*}\right)^{\prime} \eta_{t}+\omega\left(x_{t-h}^{*}\right) \eta_{t}^{\perp}
$$

In order to capture the quadratic dynamics of real bond prices, we will have to augment our state vector with the term vech $\left(x_{t} x_{t}^{\prime}\right)$. We introduce the operator $D_{n}$ such that $\operatorname{vec}()=D_{n} \operatorname{vech}()$. We also introduce $D_{n}^{+}=\left(D_{n}^{\prime} D_{n}\right)^{-1} D_{n}^{\prime}$ so that $D_{n}^{+} \operatorname{vec}\left(x_{t}^{*} x_{t}^{* \prime}\right)=\operatorname{vech}\left(x_{t}^{*} x_{t}^{* \prime}\right)$. Thus, applying properties of $\operatorname{vec}()$,

$$
\begin{aligned}
\operatorname{vech}\left(x_{t}^{*} x_{t}^{* \prime}\right) & =D_{n}^{+} \operatorname{vec}\left(K K^{\prime}+h \Sigma \Sigma^{\prime}\right)+D_{n}^{+}(H \otimes K+K \otimes H) x_{t-h}^{*} \\
& +D_{n}^{+}(H \otimes H) \operatorname{vec}\left(x_{t-h}^{*} x_{t-h}^{* \prime}\right)+D_{n}^{+} \operatorname{vec}\left(\Sigma \eta_{t} \eta_{t}^{\prime} \Sigma^{\prime}\right. \\
& \left.-h \Sigma \Sigma^{\prime}+\left(K+H x_{t-h}^{*}\right) \eta_{t}^{\prime} \Sigma^{\prime}+\Sigma \eta_{t}\left(K^{\prime}+x_{t-h}^{* \prime} H^{\prime}\right)\right) \\
& =\operatorname{vech}\left(K K^{\prime}+h \Sigma \Sigma^{\prime}\right)+D_{n}^{+}(H \otimes K+K \otimes H) x_{t-h}^{*} \\
& +D_{n}^{+}(H \otimes H) D_{n} \operatorname{vech}\left(x_{t-h}^{*} x_{t-h}^{* \prime}\right)+\nu_{t}
\end{aligned}
$$

where the errors terms are collected in

$$
\nu_{t}=D_{n}^{+}(\Sigma \otimes \Sigma) \operatorname{vec}\left(\eta_{t} \eta_{t}^{\prime}\right)-\operatorname{vech}\left(h \Sigma \Sigma^{\prime}\right)+M\left(x_{t-h}^{*}\right) \Sigma \eta_{t}
$$

and

$$
M\left(x_{t-h}^{*}\right)=D_{n}^{+}\left(I_{n x n} \otimes\left(K+H x_{t-h}^{*}\right)+\left(K+H x_{t-h}^{*}\right) \otimes I_{n x n}\right)
$$

This permits us to define a linear state space equation:

$$
s_{t}=G_{h}+\Gamma_{h} s_{t-h}+\eta_{t}^{s}
$$

in which:

$$
\begin{aligned}
& s_{t}=\left[\begin{array}{c}
x_{t}^{*} \\
\operatorname{vech}\left(x_{t}^{*} x_{t}^{* \prime}\right) \\
q_{t}
\end{array}\right], G_{h}=\left[\begin{array}{c}
K \\
\operatorname{vech}\left(K K^{\prime}+h \Sigma \Sigma^{\prime}\right) \\
\rho_{0}^{\pi} h
\end{array}\right], \eta_{t}^{s}=\left[\begin{array}{c}
\Sigma \eta_{t} \\
\nu_{t} \\
\lambda^{q}\left(x_{t-h}^{*}\right)^{\prime} \eta_{t}+\omega\left(x_{t-h}^{*}\right) \eta_{t}^{\perp}
\end{array}\right] \\
& \Gamma_{h}=\left[\begin{array}{ccc}
H & 0 & 0 \\
D_{n}^{+}(H \otimes K+K \otimes H) & D_{n}^{+}(H \otimes H) D_{n} & 0 \\
\rho_{1}^{\pi \prime} h & 0 & 1
\end{array}\right]
\end{aligned}
$$

To perform Kalman filtering, we will need the conditional moments of the state variables. We can easily see that

$$
E\left[s_{t} \mid \mathcal{F}_{t-h}\right]=G_{h}+\Gamma_{h} s_{t-h}
$$

The conditional variance $\Omega_{t-h}^{s}=\operatorname{Var}\left(s_{t} \mid \mathcal{F}_{t-h}\right)=\operatorname{Var}\left(\eta_{t}^{s}\right)=E\left[\eta_{t}^{s} \eta_{t}^{s \prime}\right]$. 


\section{Appendix C: Observation equations}

Observed variables $o_{t}$ are linear in the underlying state vector:

$$
o_{t}=a+F s_{t}+\varepsilon_{t}
$$

Using the expression for the bond prices derived earlier (and solving the differential equations), the continuously compounded yields can be expressed as:

$$
Y_{t}^{N}=a^{N}+b^{N \prime} x_{t}+\varepsilon_{t}^{N}
$$

where $a^{N}=\left[a_{3 m}^{N} \ldots a_{10 y}^{N}\right]^{\prime}$ is the stacked vector of coefficients for each maturity, and $a_{\tau}^{N}=-\frac{1}{\tau} A_{\tau}^{N}$, where $A_{\tau}^{N}$ are the pricing parameters.

The short rate forecasts are $f_{t}^{\tau}=E_{t}\left[r_{t+\tau, 3 m}\right]$ for $\tau=6 m, 12 m$. The 6 -to- 11

years ahead forecast is $f_{t}^{l o n g}=\frac{1}{5} \int_{6 y}^{11 y} E_{t}\left[r_{t+\tau, 3 m}\right] d \tau$. We can solve for these using our expressions for the yields to find:

$$
\begin{aligned}
f_{t}^{\tau} & =a_{3 m}^{n}+b_{3 m}^{N \prime}\left(I_{n x n}-e^{-\kappa \tau}\right) \mu+b_{3 m}^{N \prime} e^{-\kappa \tau} x_{t}+\varepsilon_{t}^{f \tau} \\
f_{t}^{l o n g} & =a_{3 m}^{N}+b_{3 m}^{N \prime}\left(I_{n x n}-\frac{1}{5} \kappa^{-1}\left(e^{-6 \kappa}-e^{-11 \kappa}\right)\right) \mu+b_{3 m}^{N \prime} \frac{1}{5} \kappa^{-1}\left(e^{-6 \kappa}-e^{-11 \kappa}\right) x_{t}+\varepsilon_{t}^{f l}
\end{aligned}
$$

for $\tau=6 m, 12 m$.

The inflation expectations can be expressed as:

$$
E I_{t}^{\tau}=\rho_{0}^{\pi}+\rho_{1}^{\pi \prime} \mu-\frac{1}{\tau} \rho_{1}^{\pi \prime} \kappa^{-1}\left(I_{n x n}-e^{-\kappa \tau}\right) \mu+\frac{1}{\tau} \rho_{1}^{\pi \prime} \kappa^{-1}\left(I_{n x n}-e^{-\kappa \tau}\right) x_{t}^{*}+\varepsilon_{t}^{E I}
$$

for $\tau=1,11$.

Lastly, the one-year inflation uncertainty can be expressed:

$$
\left.I U_{t}^{1 y}=C^{\prime} V C+\left(2 C^{\prime} V D\right) x_{t}^{*}+\operatorname{vec}\left(D^{\prime} V D\right)^{\prime} D_{n} \operatorname{vech}\left(x_{t}^{*} x_{t}^{* \prime}\right)\right)+\varepsilon_{t}^{I U}
$$

Thus, collecting all the coefficients of the constant terms in $a$ and the coefficients multiplying the states in $F$, we have:

$$
a=\left[\begin{array}{c}
0 \\
a^{N} \\
a^{f, 6 m} \\
a^{f, 12 m} \\
a^{f, l} \\
a^{i, 1 y r} \\
a^{i, 10 y r} \\
a^{u, 1 y r}
\end{array}\right] F=\left[\begin{array}{ccc}
0 & 0 & 1 \\
b^{N \prime} & 0 & 0 \\
b^{f 6 m} & 0 & 0 \\
b^{f 12 m} & 0 & 0 \\
b^{f l} & 0 & 0 \\
b^{i, 1 y r} & 0 & 0 \\
b^{i, 10 y r} & 0 & 0 \\
b^{u, 1 y r} & \operatorname{vec}\left(D^{\prime} V_{\tau} D\right)^{\prime} D_{n} & 0
\end{array}\right]
$$

The error vector $\varepsilon_{t}$ will have a diagonal covariance matrix. 


\section{References}

Abrahams, M., T. Adrian, R. K. Crump, and E. Moench, 2013, "Decomposing real and nominal yield curves." Federal Reserve Bank of New York Staff Reports No. 570 , October.

Ahn, D., Dittmar, R., and Gallant, A. (2002), "Quadratic term structure models: theory and evidence." Review of Financial Studies Vol. 15, No. 1, 243-288.

Ahn, D., Dittmar, R., Gallant, A., Gao, B. (2003), "Purebred or hybrid?: Reproducing the volatility in term structure dynamics." Journal of Econometrics 116, $147-180$

Ajello, Andrea, Luca Benzoni, and Olena Chyruk (2012), "Core and 'Crust': Consumer Prices and the Term Structure of Interest Rates." Working Paper Series WP-2014-11. Federal Reserve Bank of Chicago.

Ang, A., G. Bekaert and M. Wei (2007), "Do macro variables, asset markets or surveys forecast inflation better?" Journal of Monetary Economics, 54, 1163-212.

- (2008), "The term structure of real rates and inflation expectations." Journal of Finance, 63(2), 797-849.

Anh, Le and Kenneth J. Singleton (2013), "The Structure of Risks in Equilibrium Affine Models of Bond Yields." Working paper, UNC.

Argov, Eyal, David Rose, Philippe Karam, Natan Epstein, and Douglas Laxton (2007). "Endogenous Monetary Policy Credibility in a Small Macro Model of Israel." IMF working paper 207.

Bansal, R. and Ivan Shaliastovich (2012), "A Long-Run Risks Explanation of Predictability Puzzles in Bond and Currency Markets." Review of Financial Studies.

Bekaert, Geert and Xiaozheng Wang (2010), "Inflation risk and the inflation risk premium." Economic Policy October 2010 pp. 755-806.

Buraschi, Andrea and Alexei Jiltsov (2005), "Inflation Risk Premia and the Expectations Hypothesis." Journal of Financial Economics 75, 429-490.

Campbell, J. Y. and R. Shiller (1996), "A scorecard for indexed government debt," in B. S. Bernanke and J. Rotemberg (eds.), National Bureau of Economic Research Macroeconomics Annual 1996, MIT Press, Cambridge, MA, pp. 155-97.

Campbell J. Y., Sunderam A. and Viceira L., "Inflation bets or deflation hedges? The changing risks of nominal bonds." Harvard Business School Working Paper, 09-088, 2016.

Chernov, Mikhail, and Philippe Mueller (2012), "The term structure of inflation expectations." Journal of Financial Economics vol. 106, 367-394. 
Christensen, Jens H.E. , Jose A. Lopez, and Glenn D. Rudebusch (2012), "Extracting Deflation Probability Forecasts from Treasury Yields." International Journal of Central Banking, December, 21-60.

Cochrane, J. H. and Monika Piazzesi (2005), "Bond Risk Premia." American Economic Review, Vol. 94, No. 1, 138-160.

Collin-Dufresne, Pierre, Robert S. Goldstein, Christopher S. Jones, "Can interest rate volatility be extracted from the cross section of bond yields?" Journal of Financial Economics 94 (2009) 47-66.

Croushore, Dean (1993), "Introducing: The Survey of Professional Forecasters." Federal Reserve Bank of Philadelphia Business Review, November/December, 3-13.

Dai, Q., Singleton, K. (2002), "Expectations puzzle, time-varying risk premia, and affine models of the term structure." Journal of Financial Economics 63, 415-441

D'Amico, S., D. Kim and M. Wei (2016). "Tips from TIPS: the information content of Treasury inflation-protected security prices", Journal of Financial and Quantitative Analysis, forthcoming.

D'Amico S., and Thomas King, (2015), "What does anticipated monetary policy do?" Federal Reserve Bank of Chicago Working Paper 2015-10.

D'Amico S., and Athanasios Orphanides (2008), "Uncertainty and Disagreement in Economic Forecasting." Finance and Economics Discussion Series 2008-56. Federal Reserve Board.

D'Amico S., and Athanasios Orphanides (2014), "Inflation Uncertainty and Disagreement in Bond Risk Premia." Federal Reserve Bank of Chicago Working Paper No. 2014-24.

David, Alexander, and Pietro Veronesi (2013), "What Ties Return Volatilities to Price Valuations and Fundamentals?" Journal of Political Economy, vol. 21, No. 4 (August), 682-746.

Du, Wenxin, Carolin E. Pflueger, and Jesse Schreger (2016). "Sovereign Debt Portfolios, Bond Risks, and the Credibility of Monetary Policy." NBER Working Paper Series, No. 22592, September.

Duffee, G. (2002), "Term premia and interest rate forecasts in affine models." Journal of Finance 57, 405-443.

Duffee, G. (2011), "Information in (and not in) the term structure." Review of Financial Studies 24, 2895-2934.

Evans, Charles, Jonas Fisher, Francois Gourio and Spencer Krane (2015), "Risk management for monetary policy near the zero lower bound." Brookings Papers on Economic Activity, March 19, 2015 
Feldman, Ron, Kenneth Heinecke, Narayana Kocherlakota, Samuel Schulhofer-Wohl, and Thomas Tallarini (2016), "Market-Based Expectations as a Tool for Policymakers". Working Paper.

Goodfriend, Marvin (1993), "Interest Rate Policy and the Inflation Scare Problem: 1979-1992." Reserve Bank of Richmond Economic Quarterly Volume 79/1 Winter 1993.

Grishchenko, O. and J. Huang (2013), "The inflation risk premium: evidence from the TIPS market." The Journal of Fixed Income, Spring.

Gurkaynak, Refet S., Brian Sack, and Jonathan H. Wright (2006), "The U.S. Treasury Yield Curve: 1961 to the Present." Journal of Monetary Economics, vol. 54(8), 2291-2304.

Gurkaynak, Refet S., and Jonathan H. Wright (2012), "Macroeconomics and the Term Structure." Journal of Economic Literature, 50:2, 331-367.

Holston, Kathryn, Thomas Laubach and John C. Williams (2016), "Measuring the Natural Rate of Interest: International Trends and Determinants." Finance and Economics Discussion Series, 2016-073. Washington: Board of Governors of the Federal Reserve System.

Haubrich Joseph, George Pennacchi, Peter Ritchken (2012). "Inflation Expectations, Real Rates, and Risk Premia: Evidence from Inflation Swaps." Review of Finacial Studies v.25, n 5, 1588-1629.

Joslin, Scott, Marcel Priebsch, and Kenneth J. Singleton (2014), "Risk Premiums in Dynamic Term Structure Models with Unspanned Macro Risks." The Journal of Finance, vol. LXIX(3), 1197-1233, June.

Kim, Don H. (2004), "Time-varying risk and return in the quadratic-gaussian model of the term-structure." This paper is part of the author's Stanford dissertation.

Kim, Don H. (2008), "Challenges in macro-finance modeling." Federal Reserve Board Working Paper in the Finance and Economics Discussion Series 2008-06.

Kim, Don H. and Athanasios Orphanides (2012), "Term Structure Estimation with Survey Data on Interest Rate Forecasts." Journal of Financial and Quantitative Analysis, Volume 47, Issue 01, February 2012, 241-272.

Kim, Don H., and Kenneth J. Singleton (2012), "Term Structure Models and the Zero Bound: An Empirical Investigation of Japanese Yields." Journal of Econometrics, vol. 170, pp. 32-49.

Kim, H. D., Wright, J. H. (2005). "An Arbitrage-Free Three-Factor Term Structure Model and the Recent Behavior of Long-Term Yields and Distant-Horizon Forward Rates." Finance and Economics Discussion Series 2005-33. Federal Reserve Board. 
Kitsul, Y. and Jonathan H. Wright, "The Economics of Options-Implied Infation Probability Density Functions." Journal of Financial Economics, forthcoming.

Longstaff, Francis A., Matthias Fleckenstein, and Hanno Lustig. (2014). "Deflation Risk". UCLA Working paper.

Palomino, Francisco (2012). "Bond Risk Premiums and Optimal Monetary Policy," Review of Economic Dynamics, vol. 15, no. 1, pp. 19-40.

Piazzesi, Monika, and Martin Schneider (2006), "Equilibrium Yield Curves." NBER Working Paper 12609.

Piazzesi, Monika, Juliana Salomao, and Martin Schneider (2013), "Trend and Cycle in Bond Premia." Working Paper, December.

Stark, Tom (2010), "Realistic Evaluation of Real-Time Forecasts in the Survey of Professional Forecasters." Research Special Report, Federal Reserve Bank of Philadelphia, May.

Wachter, J. A. (2006), "A consumption-based model of the term structure of interest rates." Journal of Financial Economics 79 (2), 365-399.

Wright, Jonathan H. (2011), "Term Premia and Inflation Uncertainty: Empirical Evidence from an International Panel Dataset." American Economic Review, 101(4), $1514-34$. 
Table 1: $R^{2}$ from regressions with nominal yield factors

\begin{tabular}{lccc} 
Dependent Variable & $1^{\text {st }}$ factor & $1^{\text {st }}$ and $2^{\text {nd }}$ factor & $1^{\text {st }}, 2^{\text {nd }}$, and $3^{\text {rd }}$ factor \\
\hline$\pi$ & .05 & .06 & .06 \\
$E\left[\pi_{1 y}\right]$ & .83 & .84 & .84 \\
$E\left[\pi_{11 y}\right]$ & .86 & .86 & .87 \\
$\operatorname{Var}\left(\pi_{1 y}\right)$ & .49 & .49 & .51
\end{tabular}

Note: Entries show the $R^{2}$ of regressions of each of the inflation variables (in the first column) on the estimated factors from an affine term structure model.

Table 2: Summary of four alternative model specifications

\begin{tabular}{l|c} 
Model & Restrictions and Identifications \\
\hline Model Full & $\omega_{1}$ unrestricted, $\Lambda^{q}$ lower-triangular, $\rho_{1}^{N}(3)=0, \Lambda_{2 \times 2}^{N}$ \\
Model No_TVV & $\omega_{1}=0_{3 \times 1}, \Lambda^{q}=0_{3 \times 3}, \rho_{1}^{N}(3)=0, \Lambda_{2 \times 2}^{N}$ \\
Model No_IU & $\delta_{i u} \approx \infty, \omega_{1}=0_{3 \times 1}, \Lambda^{q}$ lower-triangular, $\rho_{1}^{N}(3)=0, \Lambda_{2 \times 2}^{N}$, \\
Model No_Unsp & $\omega_{1}$ unrestricted, $\Lambda^{q}$ lower-triangular, $\rho_{1}^{N}$ unrestricted, $\Lambda_{3 \times 3}^{N}$.
\end{tabular}

Table 3: $R^{2}$ from regressing with full model's factors

\begin{tabular}{lccc} 
Dependent Variable & $1^{\text {st }}$ factor & $1^{\text {st }}$ and $2^{\text {nd }}$ factor & $1^{\text {st }}, 2^{\text {nd }}$, and hidden factor \\
\hline$\pi$ & .06 & .06 & .07 \\
$E\left[\pi_{1 y}\right]$ & .80 & .83 & .90 \\
$E\left[\pi_{11 y}\right]$ & .70 & .84 & .89 \\
$\operatorname{Var}\left(\pi_{1 y}\right)$ & .44 & .47 & .83
\end{tabular}

Note: Entries show the $R^{2}$ of regressions of each of the inflation variables (in the first column) on the estimated factors $x_{t}^{*}$ from the full model. 


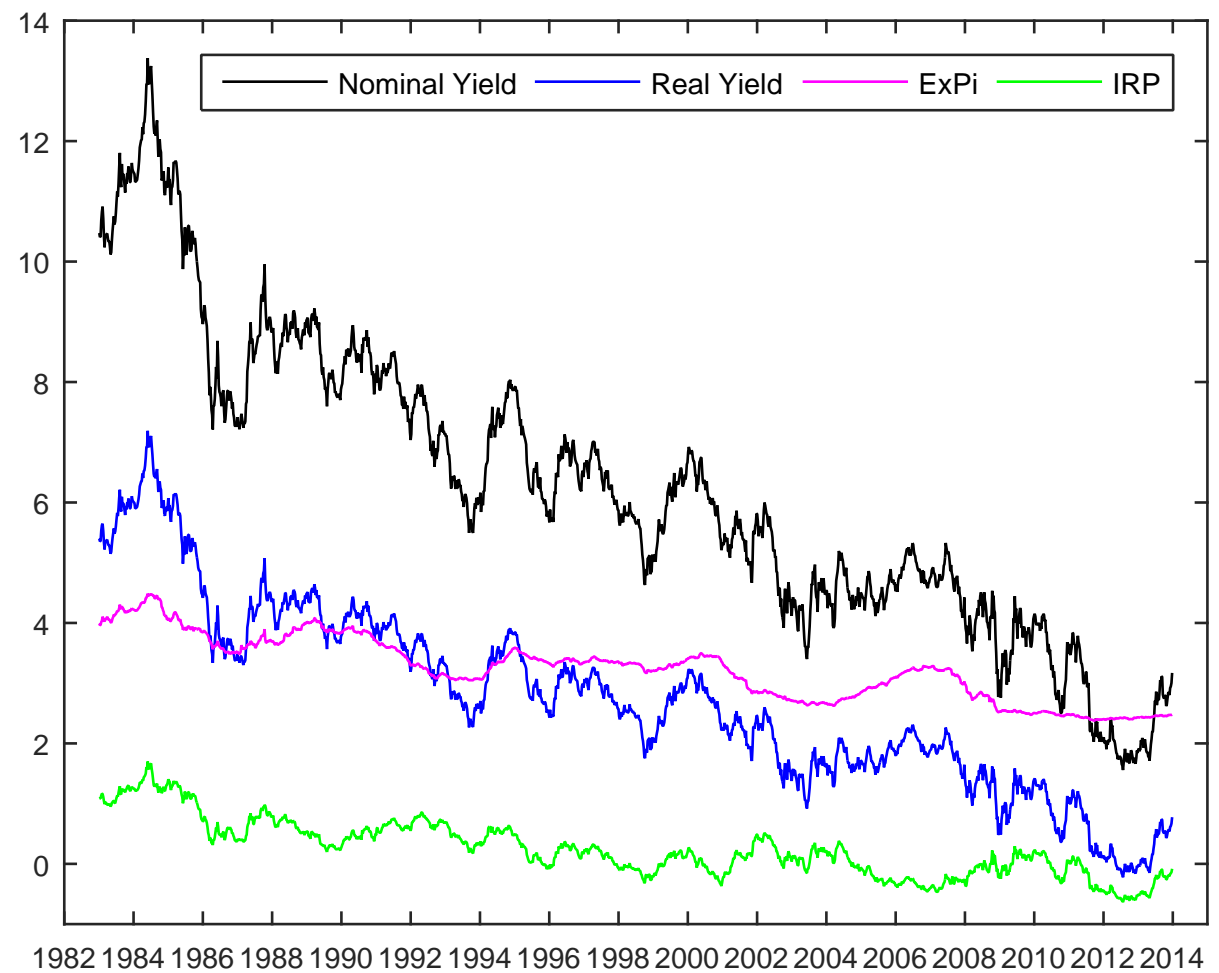

Figure 1: Decomposition of the 10-year zero-coupon nominal yield. Chart decomposes the 10-year nominal yield into the 10-year real yield (including the RRP), the expected inflation over the next 10 years $(\mathrm{ExPi})$ and the corresponding IRP implied by the full model. 


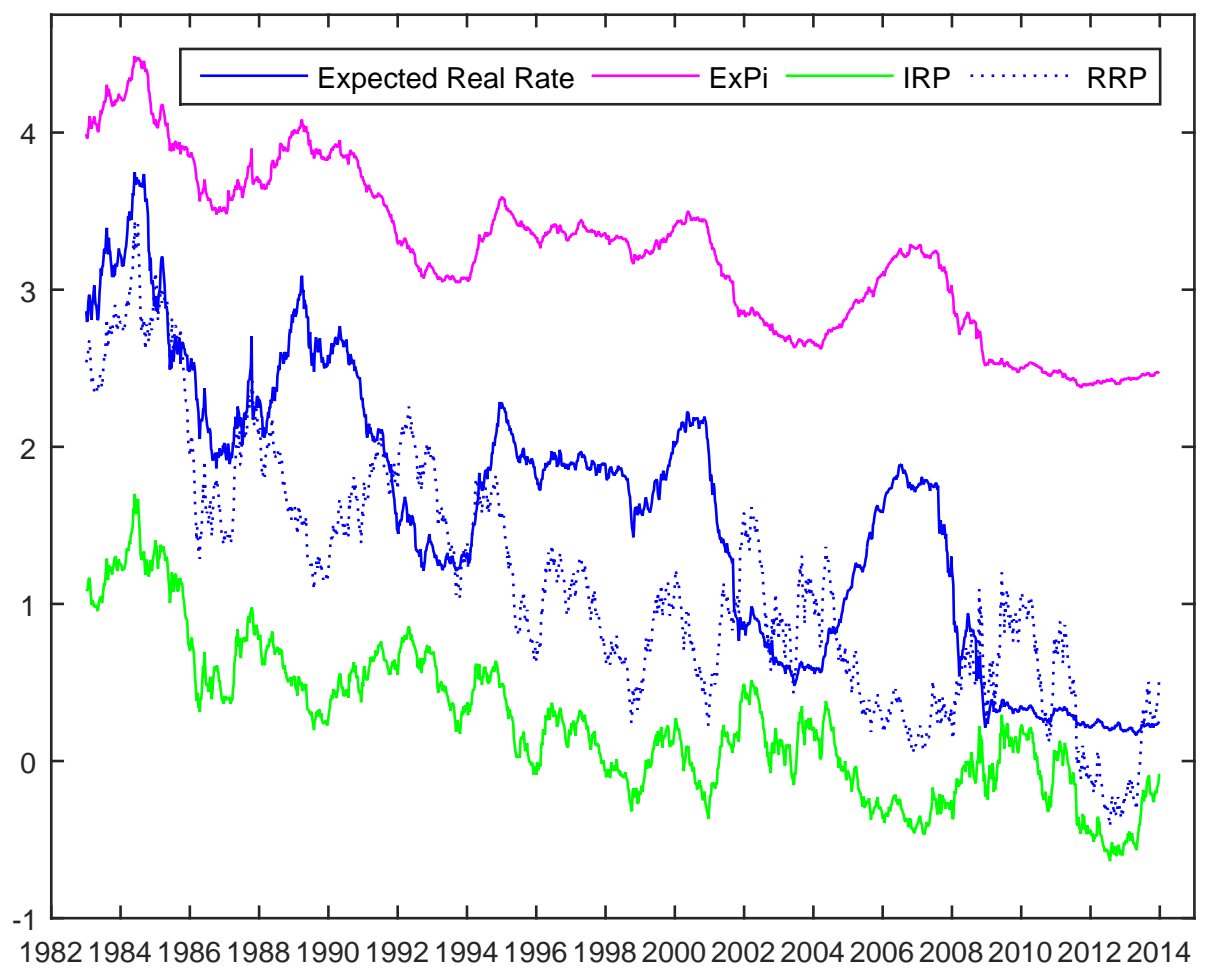

Figure 2: Expectation components and risk premia in the 10-year zero-coupon nominal yield. Chart shows the expected average short-term real interest rate over the next 10 years and the corresponding RRP together with the expected inflation over the next 10 years $(\mathrm{ExPi})$ and the corresponding IRP, implied by the full model. 

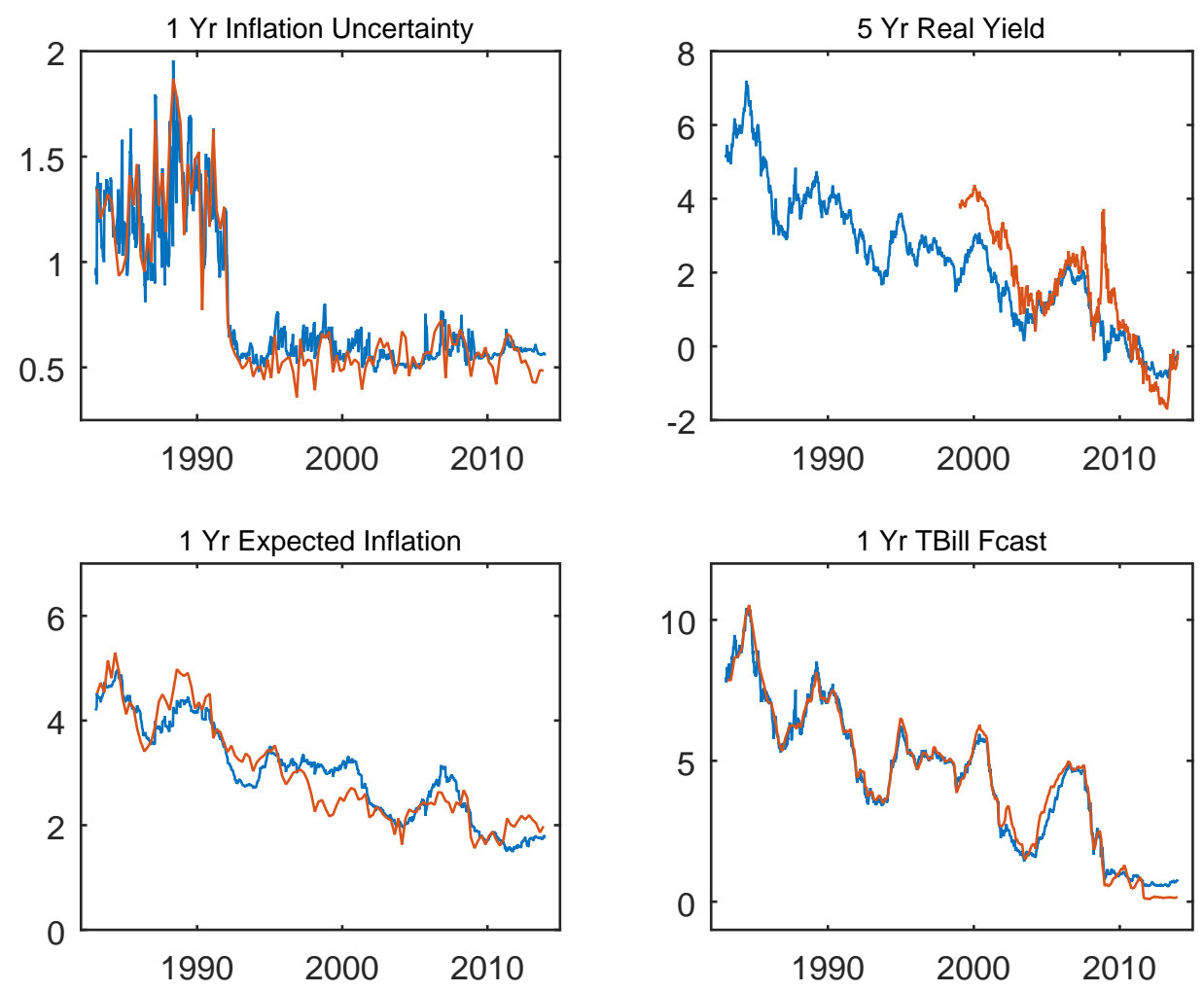

Figure 3: Overall Fit of the Full Model. Model estimates (in blue) compared with actual data and surveys (in orange). The top left panel plots the one-year surveybased inflation variance versus the model-implied inflation variance; the top right panel plots the 5-year actual TIPS yield versus the 5-year model-implied real yield; the bottom left panel plots the survey-based one-year expected inflation versus the one-year model-implied expected inflation; and the bottom right panel plots the one-year ahead survey forecast of the 3-month T-Bill rate versus the model-implied one-year ahead expectation of the 3 -month rate. 

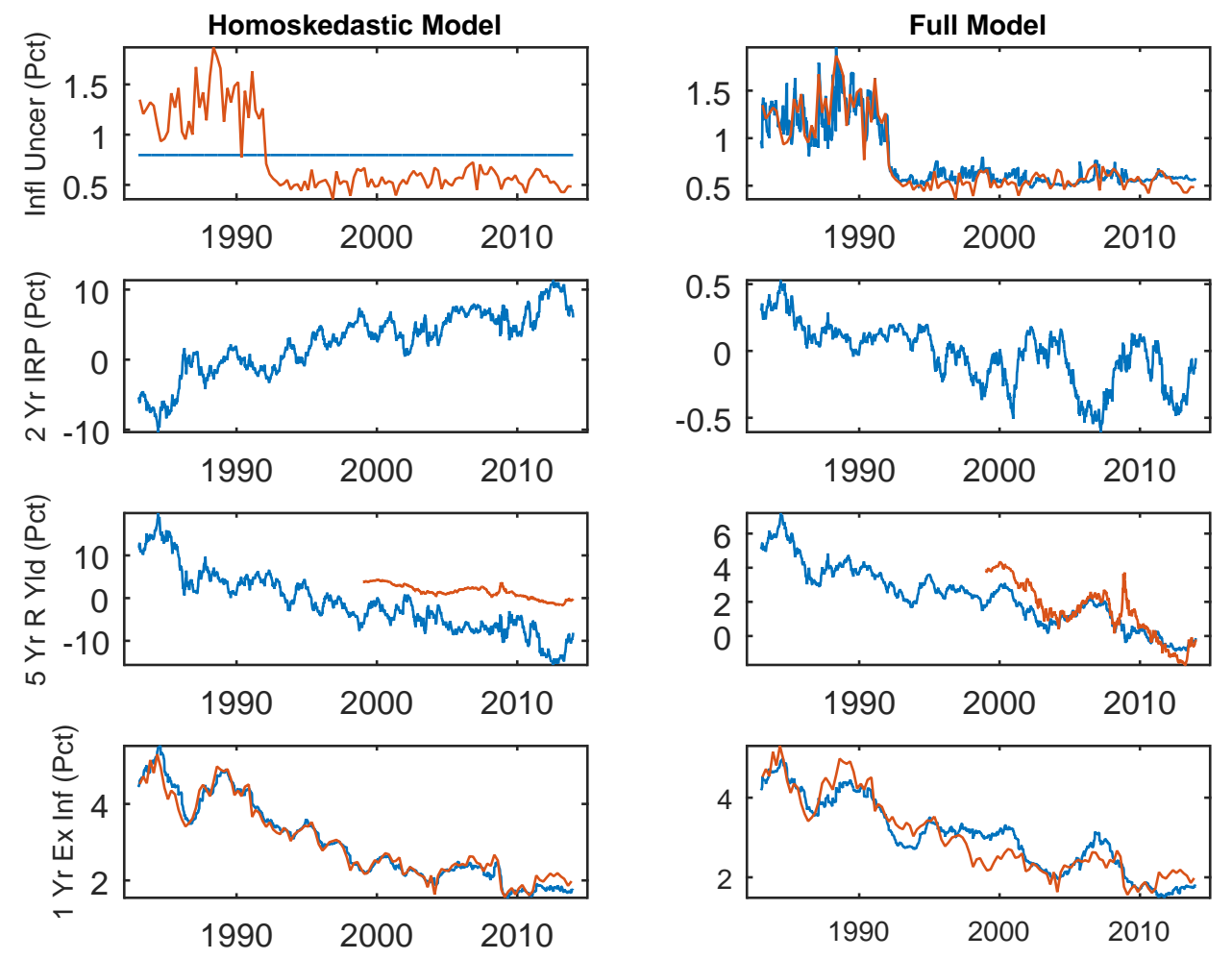

Figure 4: Comparison of homoskedastic and full models. The left panels show results from the model with homoskedastic inflation shocks and the right panels show the corresponding results from the full model. The first row plots the estimated value of the one-year inflation variance and the one-year survey-based inflation uncertainty (orange). The second row plots the estimated two-year IRP. The third row plots the model-implied 5-year real yield and the actual 5-year TIPS yield (orange). The last row plots the estimated one-year expected inflation versus the one-year ahead survey forecast of inflation (orange). 

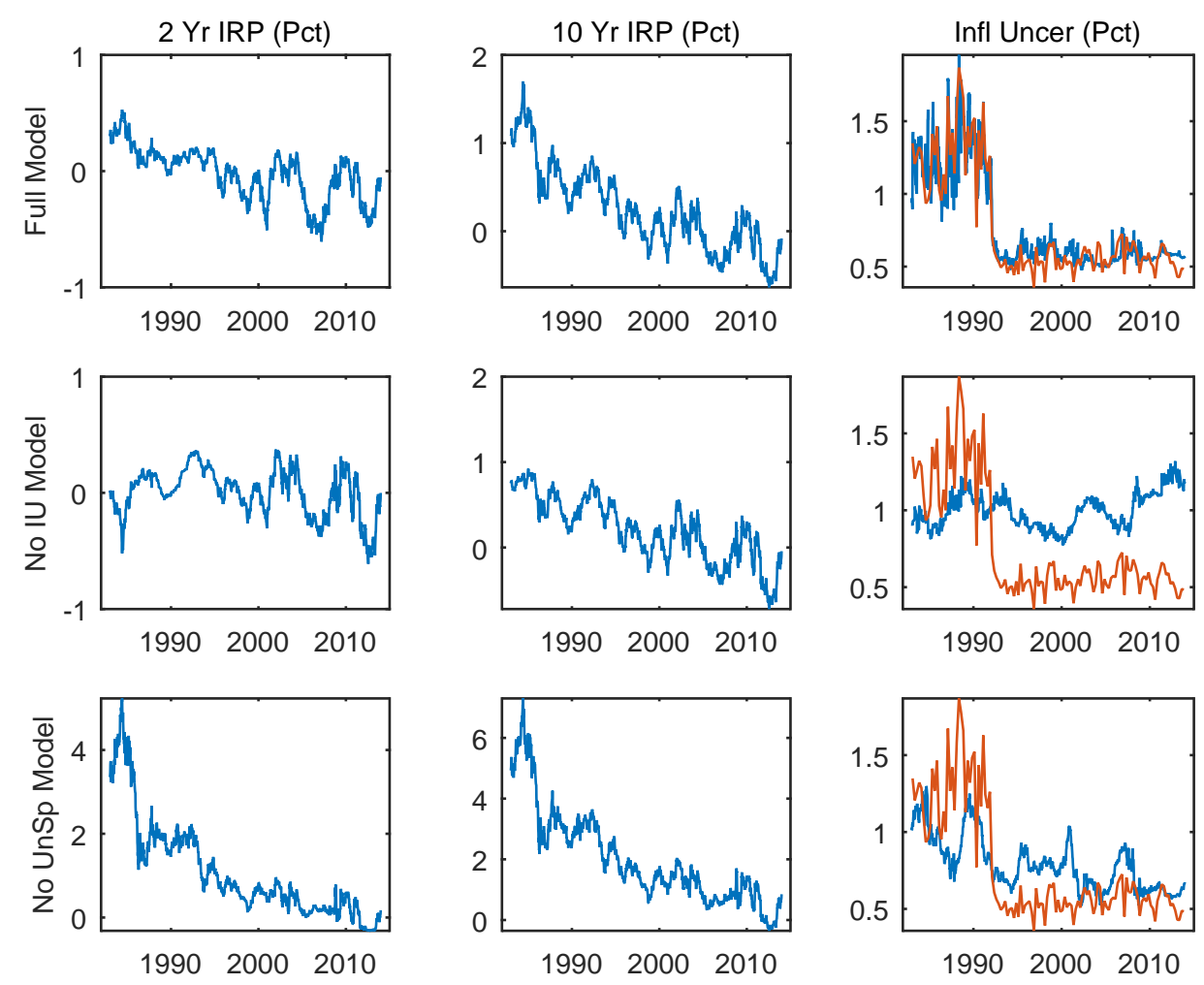

Figure 5: Inflation Risk Premium Estimates and Model Fit of Inflation Uncertainty. Each row plot results from the Full Model, No IU Model, and No Unsp Model, respectively. The left and middle panels plot the estimated values of the 2 -year and 10-year IRP. The right panels plot the one-year model-implied inflation variance together its survey counterpart (orange). 

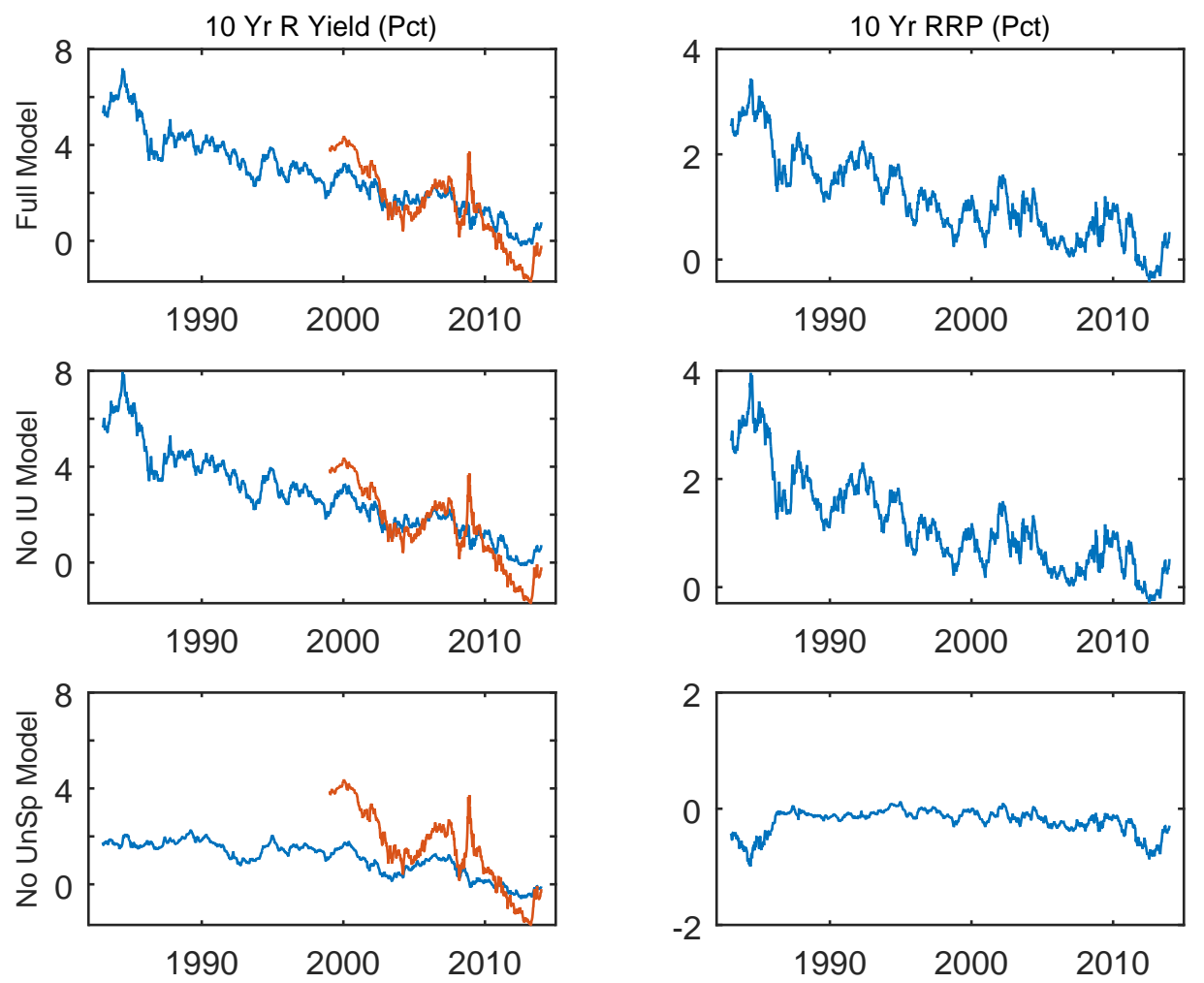

Figure 6: Model-Implied Real Yields versus TIPS yields and RRP Estimates. Each row plots results from the Full Model, No IU Model, and No Unsp Model, respectively. The left panels plot the model-implied 10-year real yield together with the actual 10-year TIPS yield (orange). The right panels plot the estimated values of the 10-year RRP. 

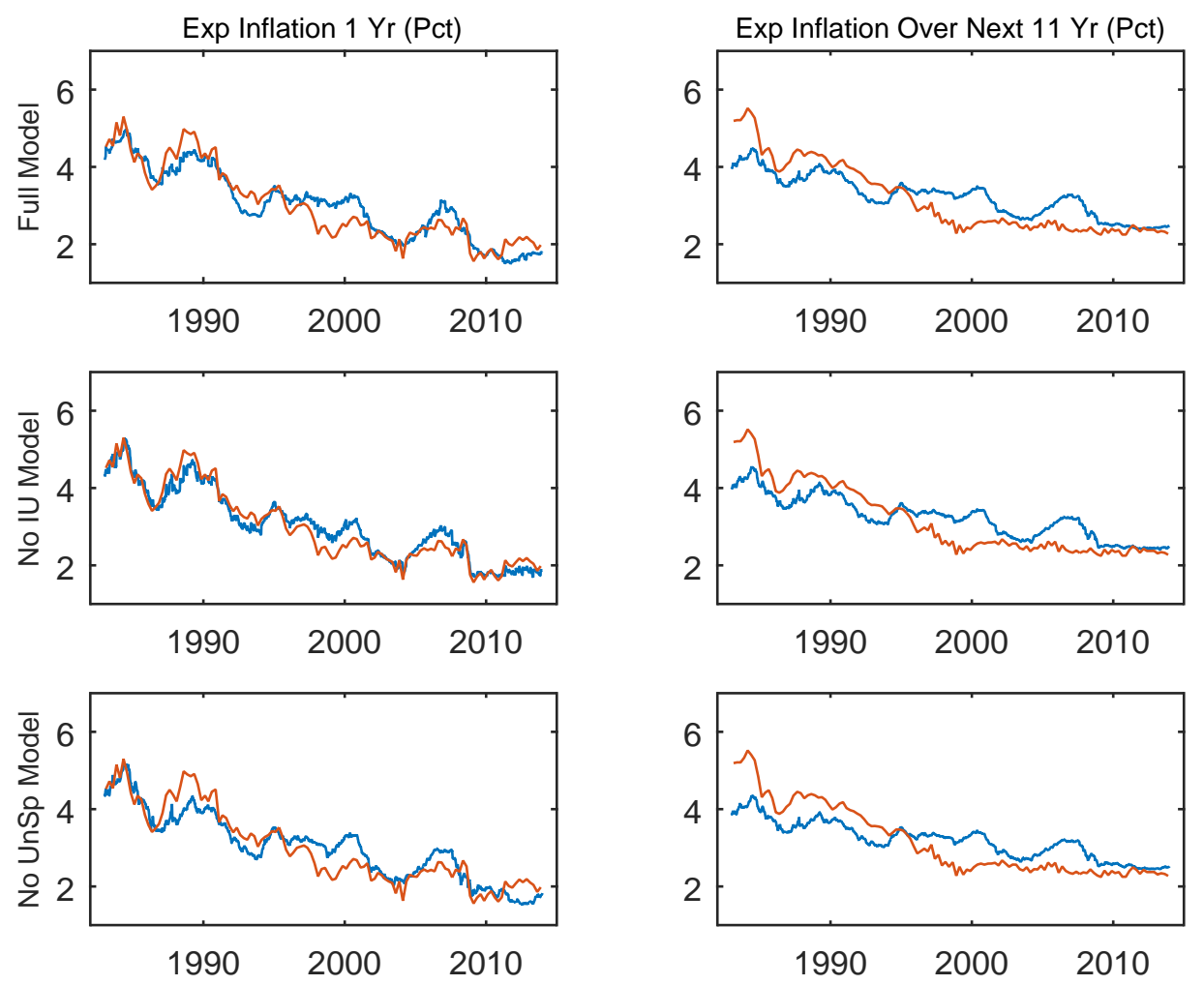

Figure 7: Model Fit of Survey Inflation Expectations at one-year and 11-year horizons. Each row plots results from the Full Model, No IU Model, and No Unsp Model, respectively. The left panels plot one-year model-implied inflation expectation together with the corresponding survey forecast (orange). The right panels plot average model-implied inflation expectation over the next 11 years together with the corresponding survey forecast (orange). 

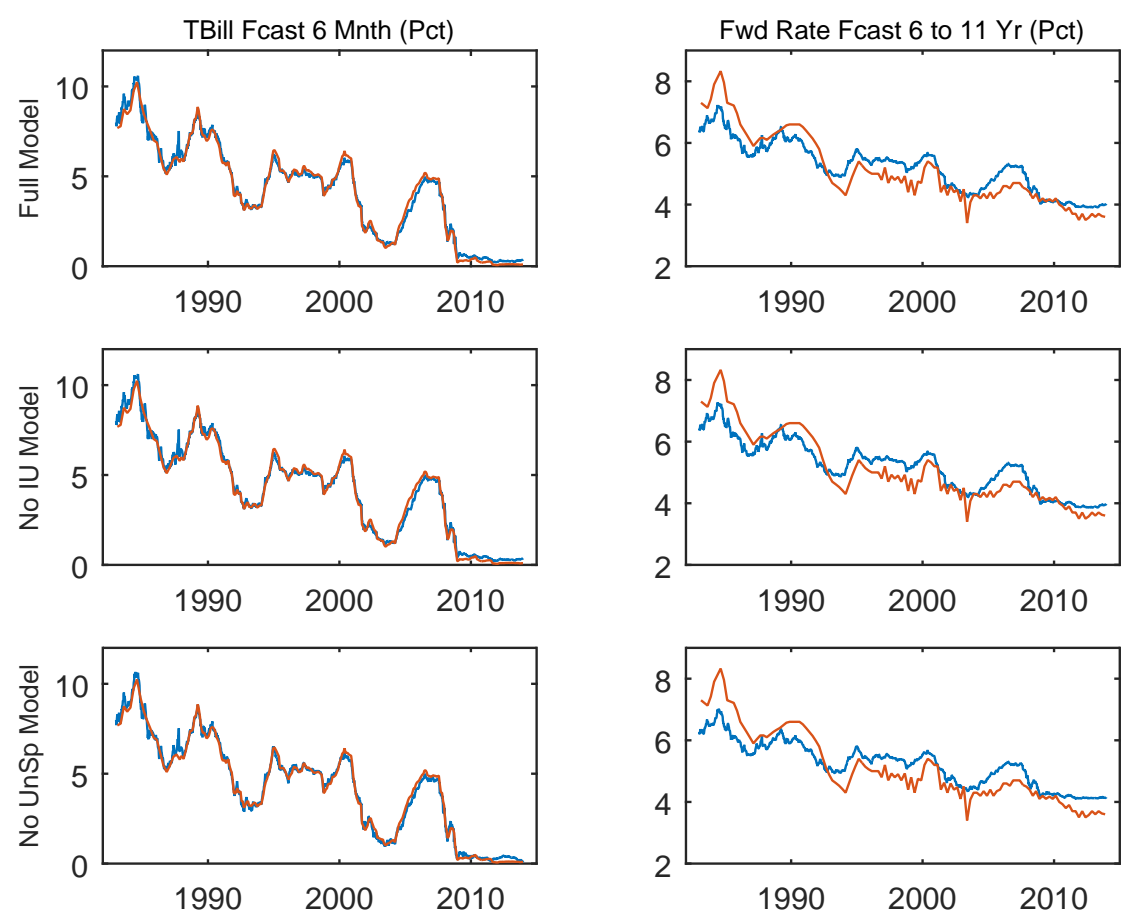

Figure 8: Model Fit of Survey Forecasts of the Short Rate at short and long horizons. Each row plots results from the Full Model, No IU Model, and No Unsp Model, respectively. The left panels plot the 6-month-ahead model-implied expectation of the 3 -month rate together with the 6 -month-ahead survey forecast of the 3 -month T-Bill rate (orange). The right panels plot the 6 -to-11 years ahead model-implied expectation of the 3-month rate together with the 6 -to-11 years ahead survey forecast of the 3 -month T-Bill rate (orange). 


\section{Working Paper Series}

A series of research studies on regional economic issues relating to the Seventh Federal Reserve District, and on financial and economic topics.

The Urban Density Premium across Establishments

WP-13-01

R. Jason Faberman and Matthew Freedman

Why Do Borrowers Make Mortgage Refinancing Mistakes?

WP-13-02

Sumit Agarwal, Richard J. Rosen, and Vincent Yao

Bank Panics, Government Guarantees, and the Long-Run Size of the Financial Sector:

Evidence from Free-Banking America

WP-13-03

Benjamin Chabot and Charles C. Moul

Fiscal Consequences of Paying Interest on Reserves

WP-13-04

Marco Bassetto and Todd Messer

Properties of the Vacancy Statistic in the Discrete Circle Covering Problem

WP-13-05

Gadi Barlevy and H. N. Nagaraja

Credit Crunches and Credit Allocation in a Model of Entrepreneurship

WP-13-06

Marco Bassetto, Marco Cagetti, and Mariacristina De Nardi

Financial Incentives and Educational Investment:

The Impact of Performance-Based Scholarships on Student Time Use

WP-13-07

Lisa Barrow and Cecilia Elena Rouse

The Global Welfare Impact of China: Trade Integration and Technological Change

WP-13-08

Julian di Giovanni, Andrei A. Levchenko, and Jing Zhang

Structural Change in an Open Economy

WP-13-09

Timothy Uy, Kei-Mu Yi, and Jing Zhang

The Global Labor Market Impact of Emerging Giants: a Quantitative Assessment Andrei A. Levchenko and Jing Zhang

WP-13-10

Size-Dependent Regulations, Firm Size Distribution, and Reallocation

WP-13-11

François Gourio and Nicolas Roys

Modeling the Evolution of Expectations and Uncertainty in General Equilibrium

WP-13-12

Francesco Bianchi and Leonardo Melosi

Rushing into the American Dream? House Prices, the Timing of Homeownership, and the Adjustment of Consumer Credit

WP-13-13

Sumit Agarwal, Luojia Hu, and Xing Huang 


\section{Working Paper Series (continued)}

The Earned Income Tax Credit and Food Consumption Patterns

WP-13-14

Leslie McGranahan and Diane W. Schanzenbach

Agglomeration in the European automobile supplier industry

WP-13-15

Thomas Klier and Dan McMillen

Human Capital and Long-Run Labor Income Risk

WP-13-16

Luca Benzoni and Olena Chyruk

The Effects of the Saving and Banking Glut on the U.S. Economy

WP-13-17

Alejandro Justiniano, Giorgio E. Primiceri, and Andrea Tambalotti

A Portfolio-Balance Approach to the Nominal Term Structure

WP-13-18

Thomas B. King

Gross Migration, Housing and Urban Population Dynamics

WP-13-19

Morris A. Davis, Jonas D.M. Fisher, and Marcelo Veracierto

Very Simple Markov-Perfect Industry Dynamics

WP-13-20

Jaap H. Abbring, Jeffrey R. Campbell, Jan Tilly, and Nan Yang

Bubbles and Leverage: A Simple and Unified Approach

WP-13-21

Robert Barsky and Theodore Bogusz

The scarcity value of Treasury collateral:

Repo market effects of security-specific supply and demand factors

WP-13-22

Stefania D'Amico, Roger Fan, and Yuriy Kitsul

Gambling for Dollars: Strategic Hedge Fund Manager Investment

Dan Bernhardt and Ed Nosal

WP-13-23

Cash-in-the-Market Pricing in a Model with Money and

Over-the-Counter Financial Markets

WP-13-24

Fabrizio Mattesini and Ed Nosal

An Interview with Neil Wallace

WP-13-25

David Altig and Ed Nosal

Firm Dynamics and the Minimum Wage: A Putty-Clay Approach

WP-13-26

Daniel Aaronson, Eric French, and Isaac Sorkin

Policy Intervention in Debt Renegotiation:

Evidence from the Home Affordable Modification Program

WP-13-27

Sumit Agarwal, Gene Amromin, Itzhak Ben-David, Souphala Chomsisengphet,

Tomasz Piskorski, and Amit Seru 


\section{Working Paper Series (continued)}

The Effects of the Massachusetts Health Reform on Financial Distress

WP-14-01

Bhashkar Mazumder and Sarah Miller

Can Intangible Capital Explain Cyclical Movements in the Labor Wedge?

WP-14-02

François Gourio and Leena Rudanko

Early Public Banks

William Roberds and François R. Velde

WP-14-03

Mandatory Disclosure and Financial Contagion

WP-14-04

Fernando Alvarez and Gadi Barlevy

The Stock of External Sovereign Debt: Can We Take the Data at 'Face Value'?

WP-14-05

Daniel A. Dias, Christine Richmond, and Mark L. J. Wright

Interpreting the Pari Passu Clause in Sovereign Bond Contracts:

It's All Hebrew (and Aramaic) to Me

WP-14-06

Mark L. J. Wright

AIG in Hindsight

WP-14-07

Robert McDonald and Anna Paulson

WP-14-08

On the Structural Interpretation of the Smets-Wouters "Risk Premium" Shock

Jonas D.M. Fisher

Human Capital Risk, Contract Enforcement, and the Macroeconomy

WP-14-09

Tom Krebs, Moritz Kuhn, and Mark L. J. Wright

Adverse Selection, Risk Sharing and Business Cycles

WP-14-10

Marcelo Veracierto

Core and 'Crust': Consumer Prices and the Term Structure of Interest Rates

WP-14-11

Andrea Ajello, Luca Benzoni, and Olena Chyruk

The Evolution of Comparative Advantage: Measurement and Implications

WP-14-12

Andrei A. Levchenko and Jing Zhang

Saving Europe?: The Unpleasant Arithmetic of Fiscal Austerity in Integrated Economies

WP-14-13

Enrique G. Mendoza, Linda L. Tesar, and Jing Zhang

Liquidity Traps and Monetary Policy: Managing a Credit Crunch

WP-14-14

Francisco Buera and Juan Pablo Nicolini

Quantitative Easing in Joseph's Egypt with Keynesian Producers

WP-14-15

Jeffrey R. Campbell 
Working Paper Series (continued)

Constrained Discretion and Central Bank Transparency

WP-14-16

Francesco Bianchi and Leonardo Melosi

Escaping the Great Recession

WP-14-17

Francesco Bianchi and Leonardo Melosi

More on Middlemen: Equilibrium Entry and Efficiency in Intermediated Markets

WP-14-18

Ed Nosal, Yuet-Yee Wong, and Randall Wright

Preventing Bank Runs

WP-14-19

David Andolfatto, Ed Nosal, and Bruno Sultanum

The Impact of Chicago's Small High School Initiative

WP-14-20

Lisa Barrow, Diane Whitmore Schanzenbach, and Amy Claessens

Credit Supply and the Housing Boom

WP-14-21

Alejandro Justiniano, Giorgio E. Primiceri, and Andrea Tambalotti

The Effect of Vehicle Fuel Economy Standards on Technology Adoption

WP-14-22

Thomas Klier and Joshua Linn

What Drives Bank Funding Spreads?

WP-14-23

Thomas B. King and Kurt F. Lewis

Inflation Uncertainty and Disagreement in Bond Risk Premia

Stefania D’Amico and Athanasios Orphanides

WP-14-24

Access to Refinancing and Mortgage Interest Rates:

WP-14-25

HARPing on the Importance of Competition

Gene Amromin and Caitlin Kearns

Private Takings

Alessandro Marchesiani and Ed Nosal

WP-14-26

Momentum Trading, Return Chasing, and Predictable Crashes

WP-14-27

Benjamin Chabot, Eric Ghysels, and Ravi Jagannathan

Early Life Environment and Racial Inequality in Education and Earnings in the United States

WP-14-28

Kenneth Y. Chay, Jonathan Guryan, and Bhashkar Mazumder

Poor (Wo)man's Bootstrap

WP-15-01

Bo E. Honoré and Luojia Hu

Revisiting the Role of Home Production in Life-Cycle Labor Supply

WP-15-02

R. Jason Faberman 


\section{Working Paper Series (continued)}

Risk Management for Monetary Policy Near the Zero Lower Bound

WP-15-03

Charles Evans, Jonas Fisher, François Gourio, and Spencer Krane

Estimating the Intergenerational Elasticity and Rank Association in the US:

Overcoming the Current Limitations of Tax Data

WP-15-04

Bhashkar Mazumder

External and Public Debt Crises

WP-15-05

Cristina Arellano, Andrew Atkeson, and Mark Wright

The Value and Risk of Human Capital

WP-15-06

Luca Benzoni and Olena Chyruk

Simpler Bootstrap Estimation of the Asymptotic Variance of U-statistic Based Estimators

WP-15-07

Bo E. Honoré and Luojia Hu

Bad Investments and Missed Opportunities?

Postwar Capital Flows to Asia and Latin America

Lee E. Ohanian, Paulina Restrepo-Echavarria, and Mark L. J. Wright

WP-15-08

Backtesting Systemic Risk Measures During Historical Bank Runs

Christian Brownlees, Ben Chabot, Eric Ghysels, and Christopher Kurz

WP-15-09

What Does Anticipated Monetary Policy Do?

WP-15-10

Stefania D'Amico and Thomas B. King

Firm Entry and Macroeconomic Dynamics: A State-level Analysis

WP-16-01

François Gourio, Todd Messer, and Michael Siemer

Measuring Interest Rate Risk in the Life Insurance Sector: the U.S. and the U.K.

WP-16-02

Daniel Hartley, Anna Paulson, and Richard J. Rosen

Allocating Effort and Talent in Professional Labor Markets

WP-16-03

Gadi Barlevy and Derek Neal

The Life Insurance Industry and Systemic Risk: A Bond Market Perspective

WP-16-04

Anna Paulson and Richard Rosen

Forecasting Economic Activity with Mixed Frequency Bayesian VARs

WP-16-05

Scott A. Brave, R. Andrew Butters, and Alejandro Justiniano

Optimal Monetary Policy in an Open Emerging Market Economy

WP-16-06

Tara Iyer

Forward Guidance and Macroeconomic Outcomes Since the Financial Crisis

Jeffrey R. Campbell, Jonas D. M. Fisher, Alejandro Justiniano, and Leonardo Melosi

WP-16-07 


\section{Working Paper Series (continued)}

Insurance in Human Capital Models with Limited Enforcement

WP-16-08

Tom Krebs, Moritz Kuhn, and Mark Wright

Accounting for Central Neighborhood Change, 1980-2010

WP-16-09

Nathaniel Baum-Snow and Daniel Hartley

The Effect of the Patient Protection and Affordable Care Act Medicaid Expansions on Financial Wellbeing

Luojia Hu, Robert Kaestner, Bhashkar Mazumder, Sarah Miller, and Ashley Wong

WP-16-10

The Interplay Between Financial Conditions and Monetary Policy Shock

WP-16-11

Marco Bassetto, Luca Benzoni, and Trevor Serrao

Tax Credits and the Debt Position of US Households

WP-16-12

Leslie McGranahan

The Global Diffusion of Ideas

WP-16-13

Francisco J. Buera and Ezra Oberfield

Signaling Effects of Monetary Policy

WP-16-14

Leonardo Melosi

Constrained Discretion and Central Bank Transparency

WP-16-15

Francesco Bianchi and Leonardo Melosi

Escaping the Great Recession

WP-16-16

Francesco Bianchi and Leonardo Melosi

The Role of Selective High Schools in Equalizing Educational Outcomes:

Heterogeneous Effects by Neighborhood Socioeconomic Status

WP-16-17

Lisa Barrow, Lauren Sartain, and Marisa de la Torre

Monetary Policy and Durable Goods

WP-16-18

Robert B. Barsky, Christoph E. Boehm, Christopher L. House, and Miles S. Kimball

Interest Rates or Haircuts?

Prices Versus Quantities in the Market for Collateralized Risky Loans

WP-16-19

Robert Barsky, Theodore Bogusz, and Matthew Easton

Evidence on the within-industry agglomeration of R\&D, production, and administrative occupations

WP-16-20

Benjamin Goldman, Thomas Klier, and Thomas Walstrum

Expectation and Duration at the Effective Lower Bound

WP-16-21 Thomas B. King 


\section{Working Paper Series (continued)}

The Term Structure and Inflation Uncertainty

WP-16-22

Tomas Breach, Stefania D’Amico, and Athanasios Orphanides 